\title{
Morphological Cell Types Projecting from V1 Layer 4B to V2 Thick and Thin Stripes
}

\author{
- Jeff Yarch, Hanna Larsen, Marcus Chen, and ®Alessandra Angelucci \\ Department of Ophthalmology and Visual Science, Moran Eye Institute, University of Utah, Salt Lake City, Utah 84132
}

In macaque visual cortex, different cytochrome oxidase stripes of area $\mathrm{V} 2$ receive segregated projections from layers (L)2/3 and $4 \mathrm{~B}$ of the primary visual cortex (V1), and project to dorsal or ventral stream extrastriate areas. Parallel V1-to-V2 pathways suggest functionally specialized circuits, but it is unknown whether these circuits arise from distinct cell types. V1 L4B includes two morphological types of excitatory projection neurons: pyramids, which carry mixed magnocellular $(\mathrm{M})$ and parvocellular $(\mathrm{P})$ information to downstream areas, and spiny stellates, which carry only M information. Previous studies have shown that, overall, V2 receives $\sim 80 \%$ of its L4B inputs from pyramids, thus receiving mixed $\mathrm{M}$ and $\mathrm{P}$ signals. However, it is unknown how pyramids and stellates distribute their outputs to the different V2 stripes, and whether different stripes receive inputs from morphologically distinct neuron types. Using viral-mediated labeling of V2-projecting L4B neurons in male macaques, we show that thick stripes receive a greater contribution of L4B inputs from M-dominated spiny stellates compared with thin stripes. Both stripe types, however, receive a much larger contribution from spiny stellates than previously shown for V2 overall, indicating that a larger amount of $\mathrm{M}$ information than previously thought flows into both the dorsal and ventral streams via the V2 thick and thin stripes, respectively. Moreover, we identify four types of V2-projecting L4B cells differing in size and complexity. Three such cell types project to both thin and thick stripes, but one type, the giant spiny-stellate neuron, resembling L4B neurons projecting to motion-sensitive area MT, was only found to project to thick stripes.

Key words: cytochrome oxidase; Macaque; primary visual cortex; pyramidal cells; secondary visual area; spiny stellate cells

\section{Significance Statement}

Area V1 partitions visual information into functionally specialized parallel pathways which terminate into distinct stripes of area V2. We asked whether V1 inputs to different V2 stripes arise from morphologically different cell types. V1 layer (L)4B has two cell types: pyramids, which carry both magnocellular $(\mathrm{M})$ and parvocellular $(\mathrm{P})$ visual signals, and spiny stellates, which carry only $\mathrm{M}$ signals. We find that $\mathrm{V} 2$ thick stripes, which project to areas processing object motion, receive a larger fraction of L4B input from M-dominated stellates compared with thin stripes, which project to areas processing object attributes. We also identify four morphological types of V2-projecting L4B neurons, suggestive of four functionally specialized cell types.

\section{Introduction}

A mechanistic understanding of cortical computations requires knowledge of the morphological and functional diversity of cortical neurons. Historically, distinct cell types have been initially

\footnotetext{
Received May 10, 2019; revised July 16, 2019; accepted July 19, 2019.

Author contributions: J.Y. and A.A. designed research; J.Y. and A.A. performed research; J.Y., H.L., and M.C. analyzed data; J.Y. and A.A. wrote the paper.

This work was supported by Grants from the National Institute of Health (NEI R01 EY019743 and R01 EY026812, NINDS BRAIN U01 NS099702), the National Science Foundation (IOS 1755431, EAGER 1649923), and the University of Utah Neuroscience Initiative to A.A., and by a Grant from Research to Prevent Blindness and a Core Grant from the NIH (NEI P30 EY014800) to the Department of Ophthalmology, University of Utah. We thank Drs. Sam Merlin and Frederick Federer for help with experiments, Drs. Lauri Nurminen and Maryam Bijanzadeh for thoughtful comments on data analysis, Mike Fiedel and Anny Pham for cell identification analysis, and Kesi Sainsbury for expert technical assistance.

The authors declare no competing financial interests.

Correspondence should be addressed to Alessandra Angelucci at alessandra.angelucci@hsc.utah.edu.

https://doi.org/10.1523/JNEUROSCI.1096-19.2019

Copyright $\odot 2019$ the authors
}

identified on the basis of unique morphologies and, subsequently, associated with distinct functions. A classic example are the midget and parasol retinal ganglion cells (RGCs), which were initially identified morphologically (Watanabe and Rodieck, 1989; Rodieck and Watanabe, 1993), and subsequently found to have different physiological properties (Kaplan and Shapley, 1986; Dacey et al., 2003). Further research discovered that these two RGC types underpin the parvocellular $(\mathrm{P})$ and magnocellular (M) processing pathways, respectively, which constitute anatomically separate inputs from the retina to the primary visual cortex (V1; Hendrickson et al., 1978; Schiller and Malpeli, 1978; Blasdel and Lund, 1983; Dacey, 2000). The larger dendritic fields of parasol neurons underlie their larger receptive fields, whereas the smaller dendritic fields of midget cells underpin the high spatial resolution of the $\mathrm{P}$ pathway (Xu et al., 2001).

Layer (L)4B of macaque V1 includes two morphological types of excitatory projection neurons, pyramidal and spiny stellate 
cells that project to multiple extrastriate areas, including MT and V2 (Livingstone and Hubel, 1987; Shipp and Zeki, 1989; Krubitzer and Kaas, 1990). Spiny stellate neurons have dendritic fields confined to $\mathrm{L} 4 \mathrm{~B}$ and receive $\mathrm{M}$-dominated input directly from L4C $\alpha$ (Yoshioka et al., 1994; Yabuta and Callaway, 1998; Yabuta et al., 2001). L4B pyramidal cells, instead, receive $M$ input on their basal dendrites in $\mathrm{L} 4 \mathrm{~B}$, via direct $\mathrm{L} 4 \mathrm{C} \alpha$ afferents, but are also able to integrate M-dominated inputs from $\mathrm{L} 4 \mathrm{C} \alpha$ and $\mathrm{P}$-dominated inputs from $\mathrm{L} 4 \mathrm{C} \beta$ in the layers above $4 \mathrm{~B}$, where their apical dendrite ascends (Yabuta et al., 2001). Identifying the projection targets of L4B pyramids and spiny stellate neurons can, thus, provide insight into how $\mathrm{M}$ and $\mathrm{P}$ signals are relayed to areas downstream of V1. Previous research has shown that motion-sensitive area MT receives $\sim 80 \%$ of its $\mathrm{L} 4 \mathrm{~B}$ input from spiny stellates, and larger-sized cells, suggesting that MTprojecting $\mathrm{L} 4 \mathrm{~B}$ neurons are specialized for fast transmission of $\mathrm{M}$ signals. In contrast, area $\mathrm{V} 2$ receives $\sim 80 \%$ of its $\mathrm{L} 4 \mathrm{~B}$ input from pyramids, and smaller-sized cells, suggesting that V2-projecting L4B neurons are specialized for slower transmission of mixed $\mathrm{M}$ and P signals (Nassi and Callaway, 2007).

One limitation of this previous study is that retrograde viral injections to label $\mathrm{V} 1$ projection neurons were made blindly into V2. However, V2 consists of distinct cytochrome oxidase (CO) stripe compartments, which receive segregated projections from V1 (Livingstone and Hubel, 1988; Sincich and Horton, 2002; Federer et al., 2009), show distinct functional specialization, and project to different extrastriate areas (DeYoe and Van Essen, 1985; Shipp and Zeki, 1985). For example, thin stripes receive input from V1 CO blob columns, contain a systematic representation of hue (Xiao et al., 2003), and project to ventral-stream area $\mathrm{V} 4$, specialized in processing object attributes such as shape and color (Ungerleider and Haxby, 1994). Instead, thick stripes receive input from $\mathrm{V} 1$ inter-blob columns, contain maps of motion direction (Lu et al., 2010) and retinal disparity (Chen et al., 2008), and project to dorsal-stream area MT, specialized in the processing of object motion. Thus, although V2 overall receives L4B input mostly from pyramids, but also spiny stellates, the proportion of each cell type projecting to the different stripes remains unknown. Moreover, although we know that different V2 stripes receive inputs largely from separate populations of V1 neurons (Sincich and Horton, 2002, 2005; Federer et al., 2009, 2013), it remains unclear whether these populations differ morphologically.

Here, we have used a green fluorescent protein-expressing, glycoprotein-deleted rabies virus (Wickersham et al., 2007), GdRV-GFP, to obtain Golgi-like fills of V1 L4B neurons projecting to thick or thin stripes, and fully reconstructed these cells' dendritic processes. We find that thick stripes receive a greater contribution of input from spiny stellates than thin stripes, but spiny stellates contribute a much larger fraction of L4B inputs to both stripe types than previously thought. Additionally, we identify four types of V2-projecting L4B cells distinguishable on the basis of size and complexity. Although three of these cell types project to both thin and thick stripes, we discovered a group of giant spiny stellate cells, similar to those projecting to MT, which project only to thick stripes.

\section{Materials and Methods}

\section{Experimental design}

To label at high resolution the soma and dendrites of V1 L4B neurons projecting to specific V2 stripes, we made injections of GdRV-EGFP (based on the SAD-B19 strain) into thick or thin stripes of macaque area V2, identified in vivo by intrinsic signal optical imaging. This virus acts as a retrograde tracer, infecting neurons only at their synapses, and, because it lacks the glycoprotein, which is necessary for trans-synaptic infection, it continues to replicate inside infected cells producing vast amounts of GFP; as a result cells are labeled at high resolution (Wickersham et al., 2007). The GFP label was enhanced immunohistochemically, and V1 L4B neurons were reconstructed through serial tissue sections, to examine their morphological characteristics (as by Yarch et al., 2017).

\section{Animals}

We made a total of 17 injections of GdRV-EGFP into six adult male macaque monkeys (Macaca fascicularis), and selected for analysis only those cases for which the viral injection was confined to a V2 thick or thin stripe, and produced high-quality labeling of L4B neurons, namely five injections into thick stripes and four injections into thin stripes, from a total of five animals (Table 1). Injections were targeted at the exposed portion of dorsal V2, posterior to the lunate sulcus.

\section{Surgical and tracer injection procedures}

All experimental procedures were in accordance with protocols approved by the University of Utah Institutional Animal Care and Use Committee. Surgical procedures were performed as described previously (Federer et al., 2013). Briefly, animals were pre-anesthetized with ketamine $(10-25 \mathrm{mg} / \mathrm{kg}, \mathrm{i} . \mathrm{m}$.$) , intubated, and artificially ventilated. The$ head of each animal was fixed by positioning the animal in a stereotaxic apparatus. Isoflurane $(1.0-2.5 \%)$ was used to maintain anesthesia, and depth of anesthesia was assessed continuously by monitoring end-tidal $\mathrm{CO}_{2}$, saturation of peripheral oxygen, electrocardiogram, blood pressure, withdrawal, and corneal reflexes. Temperature was maintained $\sim 37-38^{\circ} \mathrm{C}$ by wrapping the animal in a water blanket. To expose area $\mathrm{V} 2$ and the anterior half of $\mathrm{V} 1$ on the opercular surface, a large $(\sim 15 \times 10$ $\mathrm{mm}$ ) craniotomy and durotomy were performed posterior to the lunate sulcus, then the craniotomy was filled with $3 \%$ agar and sealed using a glass coverslip glued to the skull. Isoflurane was turned off, anesthesia maintained with sufentanil citrate $(5-10 \mu \mathrm{g} / \mathrm{kg} / \mathrm{h})$, and paralysis induced by continuous infusion of vecuronium bromide $(0.1-0.3 \mathrm{mg} / \mathrm{kg} / \mathrm{h})$ to prevent eye movements. The pupils were dilated with topical atropine, the eyes were protected with gas-permeable contact lenses and refracted, and optical imaging was started. Once functional regions corresponding to the V2 stripes were identified (see Optical imaging), the glass coverslip was removed, and GdRV-EGFP (donated by E. Callaway, Salk Institute or purchased from the Salk Institute Viral Vector Core) was pressure injected into V2 using a picospritzer and glass micropipettes of 35-45 $\mu \mathrm{m}$ tip diameter. To obtain sparse labeling of cells in V1, which would facilitate single neuron reconstructions, we injected small volumes (375$500 \mathrm{nl}$ ) of the viral solution at 0.6 or $1 \mathrm{~mm}$ depth, over a $30-40 \mathrm{~min}$ period. The pipette was left in place for 5-10 min on completion of the injection before being retracted. On completion of the viral injections, 4 of the 6 animals were kept under anesthesia for an additional 3-6 d, during which additional optical imaging was performed, and finally euthanized with sodium pentobarbital ( $150 \mathrm{mg} / \mathrm{kg}$, i.v.), and perfused transcardially with saline for $3 \mathrm{~min}$, followed by fixative. Two of the animals were instead recovered from anesthesia and paralysis, and after a survival period of $4 \mathrm{~d}$, were re-anesthetized and paralyzed as described, and optical imaging was performed over a period of an additional $4 \mathrm{~d}$, after which the animals were euthanized and perfused.

\section{Optical imaging}

Intrinsic signal optical imaging was performed to identify the thick and thin V2 stripes. Specifically, imaging for ocular dominance enabled us to identify the V1-V2 border, imaging for stimulus orientation identified the thick and pale stripes (which have well defined orientation maps, unlike thin stripes; Figs. $1 B, 2 B, C$ ), and imaging for color delineated the thin stripes (Figs. 1A, 2A, C; Lu and Roe, 2008). Acquisition of intrinsic signals was performed using the Imager 3001 and VDAQ software (Optical Imaging) under red-light illumination $(630 \mathrm{~nm})$. Orientation maps were obtained by presenting full-field, high-contrast (100\%), achromatic drifting square-wave gratings of eight different orientations and 1.0-2.0 cycles $/{ }^{\circ}$ spatial frequency, moving back and forth at $1.5-2.0 \mathrm{~Hz}$ in directions perpendicular to the grating orientation. Responses to the same oriented stimuli were averaged across trials, first-frame subtracted, and 


\section{A Color}

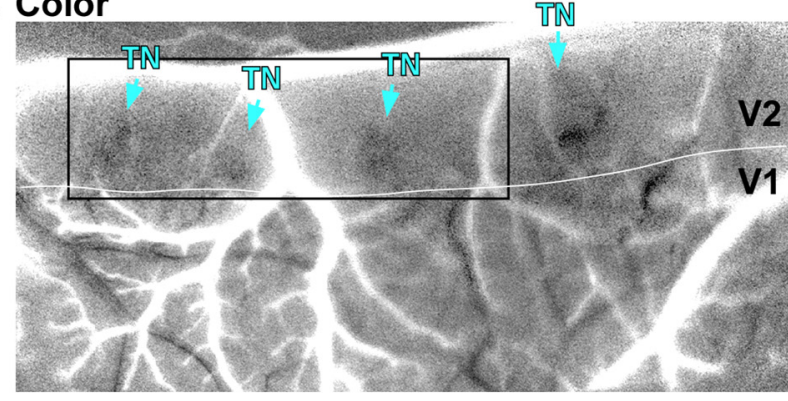

B Orientation

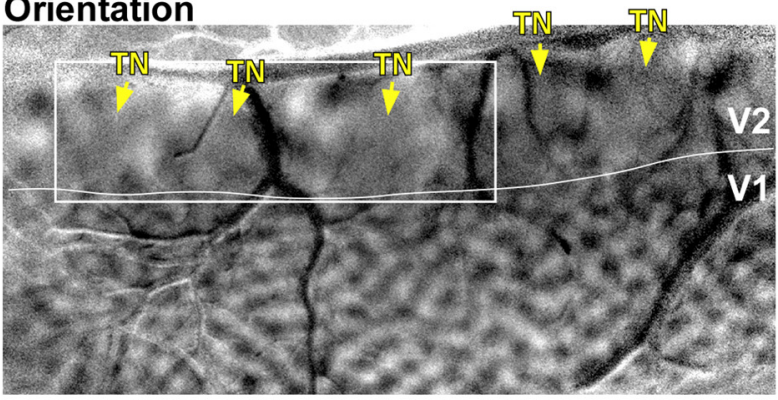

C CO (superficial section)

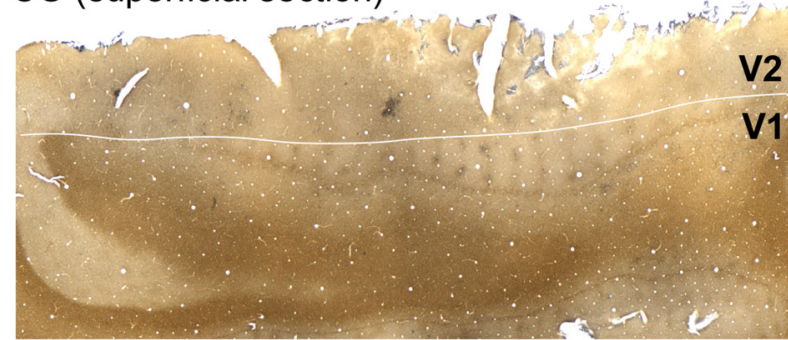

D Orientation + CO (overlay)

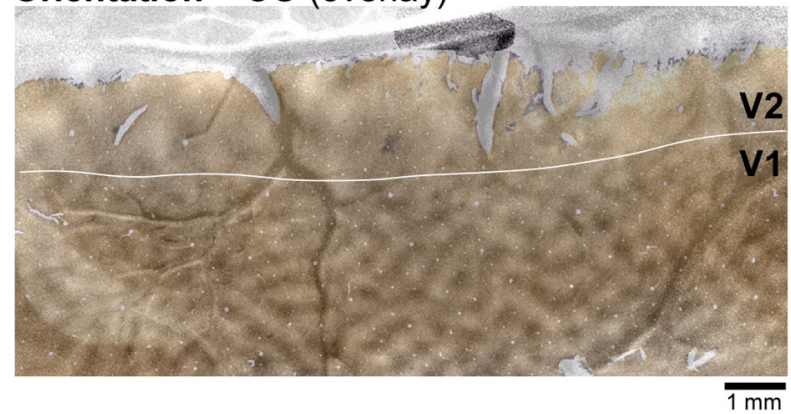

Figure 1. Alignment of $\mathrm{CO}$ staining with in vivo optical images. Case MK368-M and -W. A, Difference color map. Stronger optical signals correspond to thin stripes (cyan arrows). B, Difference orientation map. Regions lacking orientation domains correspond to thin (TN) stripes (yellow arrows). Boxes outlined in $\boldsymbol{A}$ and $\boldsymbol{B}$ indicate regions are shown at higher magnification in Figure $2 A$ and $B$, respectively. $C$, A superficial histological section stained for $C 0 . D$, Overlay of the $C O$ section in $\boldsymbol{C}$ and the optical image in $(\boldsymbol{B})$ demonstrates good alignment of superficial blood vessels. White contour in $\boldsymbol{A}-\boldsymbol{D}$ indicate the V1/V2 border.

orientation difference images were generated by subtracting responses to two orthogonal orientations. Imaging for color responses was performed by flashing red-green, blue-yellow, and black-white pairs of full-field squares every $500 \mathrm{~ms}$. Averaged color responses were then subtracted from the averaged response to the blank and the achromatic stimuli. Thin stripes were identified as regions with poor orientation signals and strong color responses, and thick stripes as the middle of the regions containing strong orientation signals and no color responses (Figs. $1 A, B, 2 A-C$ ). In each case, reference images of the surface vasculature were taken $<546$ $\mathrm{nm}$ illumination (green light); these images were later used to align the surface blood vessels in the top histological tissue section to the surface

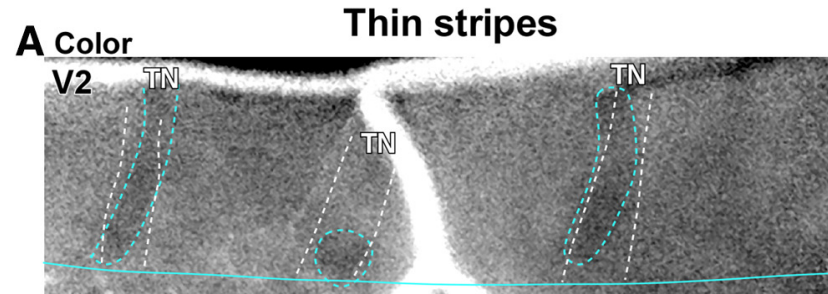

\section{B Orientation}
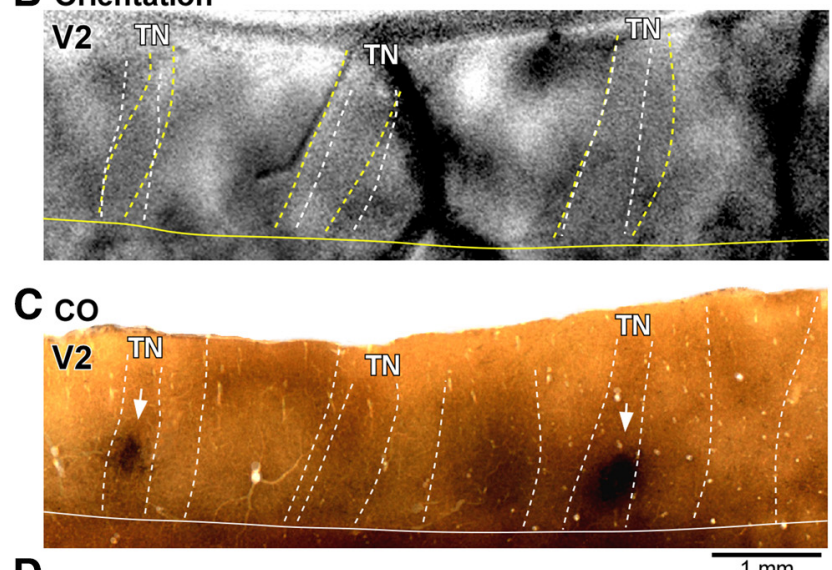

D
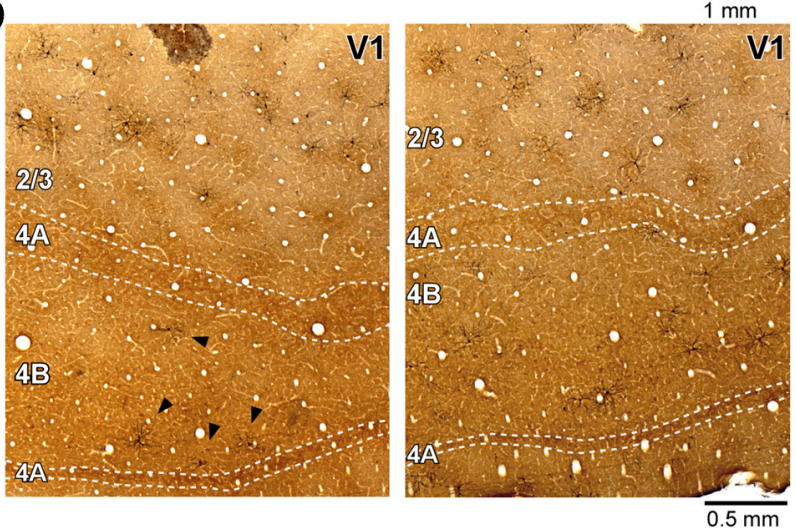

Figure 2. Injection sites in V2 thin stripes and resulting expression of GFP in V1 L4B neurons. Case MK368-M and -W. A, Difference color map in area V2 obtained by subtracting averaged responses to red-green and blue-yellow pairs of full-field square stimuli from responses to achromatic black-white square pairs. Dashed cyan contours delineate regions of strong color responses; dashed white contours are outlines of the thin (TN) stripes in $C 0$ staining $(\boldsymbol{C})$, which were superimposed onto the optical maps by aligning the superficial blood vessels in the top histological section with images of the surface vasculature (as in Fig. 1). Solid contour here and in $\boldsymbol{B}$ and $\boldsymbol{C}$ delineates the V1/V2 border. $\boldsymbol{B}$, Difference orientation map obtained from the same region of $\mathrm{V} 2$ as in $\boldsymbol{A}$ by subtracting responses to achromatic luminance gratings of $90^{\circ}$ orientation from gratings of $0^{\circ}$ orientation. Dashed yellow contours delineate regions lacking orientation responses, which overlap well with the thin stripes as defined in C 0 staining (dashed white contours). C, Micrograph of two example viral injection sites (arrows) on a merged stack of tangential sections through V2 stained for $C O$ and immunoreacted with DAB to enhance GFP signals. The injections are located in thin stripes. Dashed white contours delineate thick and thin stripes. Scale bar is valid for $A-C . D$, Micrographs of two adjacent sections through V1 stained for $\mathrm{C} 0$ and immunoreacted for GFP, showing GFP-labeled cells (black cells) within C 0 blobs in L2/3, and in $L A B$ (those on the left are marked by arrowheads) resulting from the thin stripe injections shown in $C$. Dashed white contours delineate layer boundaries and layers are indicated to the left of each panel. Scale bar valid for both panels in $\boldsymbol{D}$.

blood vessels in the optical maps obtained in vivo for postmortem identification of injection site location on CO-stained tissue (Fig. 1C,D).

\section{Histology}

The brain was fixed by transcardial perfusion with $0.5 \%$ paraformaldehyde (PFA) in $0.1 \mathrm{~m}$ phosphate buffer for $5 \mathrm{~min}$ in three animals, and $4 \%$ PFA for 15 min in two animals. In the first three animals, V1 was dis- 
sected away from $\mathrm{V} 2$ by cutting along the $\mathrm{V} 1-\mathrm{V} 2$ border under a dissecting microscope. The V1 block was postfixed in 4\% PFA for 1-2 h, immersed in $30 \%$ sucrose for cryoprotection, embedded in agar, and frozen-sectioned at $40 \mu \mathrm{m}$ in a pia-to-white matter plane parallel to the V1-V2 border. This plane was chosen to best reveal V1 laminae. Instead, to best reveal the CO stripe pattern, the V2 blocks for these three cases were unfolded, flattened, postfixed between glass slides for $1-2 \mathrm{~h}$, and sectioned tangentially to the pial surface at $40 \mu \mathrm{m}$. In the other two animals, a block containing both V1 and V2 was gently flattened in a plane parallel to the imaging camera, postfixed between glass slides, and sectioned tangentially at $40 \mu \mathrm{m}$. In two cases, alternate tissue sections from the V1 block (one case) or the V1/V2 block (the other case) were stained for CO (Sigma-Aldrich) to reveal layers and CO compartments, and then the same sections were immunoreacted to enhance GFP signals using DAB (Vector Laboratories; RRID:AB_2336382), whereas all remaining sections were only immunoreacted for GFP. In a third case, all V1 sections were immunoreacted for GFP and counterstained with fluorescent Nissl stain (Neuro Trace diluted 1:100; Invitrogen) to reveal layers. In the remaining two cases, all sections were stained and immunoreacted for both CO and GFP, respectively. The sections from the separated V2 blocks were stained for CO and immunoreacted for GFP to reveal the stripe location of the injection sites. Digitized images of the CO stripes were taken on wet mounted sections before immunoreacting the same sections, and, in most cases, again after GFP immunohistochemistry. Immunohistochemistry to enhance and permanently stain GFP signals was performed by incubating sections for $48 \mathrm{~h}$ in primary antibody (1:2000 chicken anti-GFP; Aves Labs; RRID:AB_10000240), then for $1 \mathrm{~h}$ in 1:200 biotinylated donkey anti-chicken secondary IgG (Jackson Laboratories; RRID:AB_2313596), followed by a standard nickel-enhanced $\mathrm{ABC}-\mathrm{DAB}$ reaction (yielding a black reaction product), using an ABC-avidin-peroxidase kit (Vector Laboratories; RRID:AB_2336382).

\section{Data analysis}

Stripe location of injection sites. Viral injection sites were identified as a region of black glial-like cell label visible around the pipette track (Figs. $2 C, 3 A$ ). A composite injection site was obtained by aligning, using radial blood vessels, the outlines of the injection site in each section throughout the depth of the cortex. To determine the location of these injection sites with respect to $\mathrm{V} 2$ stripes, $\mathrm{CO}$ staining was first digitized at low magnification; then, using IRtweak warping software (NCRtoolset, Scientific Computing and Imaging Institute, University of Utah; RRID:SCR_014639; Anderson et al., 2009) three to six images of CO sections were aligned using the radial blood vessels as reference, and then merged in Adobe Photoshop (using the multiply function). The V2 stripe pattern is much clearer in these composite images than in any single $\mathrm{CO}$-stained section where parts of stripes may be missing (Federer et al., 2009, 2013; Yarch et al., 2017; Fig. 2C). Finally, the composite outline of each injection site was aligned to the $\mathrm{CO}$ image stack, using radial blood vessels. From these images, we selected the injection sites clearly confined to a thick or thin stripe for further analysis. As further verification of injection site location, we aligned, using radial blood vessels, the composite injection sites to the most superficial tissue section containing the surface vessels (which run tangentially to the cortical surface), and finally aligned the injection sites to the optical maps, by alignment of the surface vessels in the histological section and the image of the cortical surface obtained under green light (Fig. 1C,D).

Selection and reconstruction of $L 4 B$ neurons. The location of labeled neurons in L4B was assessed by CO or, in one case, fluorescent Nissl stains. Cell bodies were either located in the same $\mathrm{CO}$ or Nissl stained section, or their location in L4B was determined by alignment to an adjacent $\mathrm{CO}$ stained section. To avoid sampling bias, for all cases, except one, we classified every labeled L4B neuron as spiny stellate or pyramid. In one case (MK340), the label was very dense and some cells appeared incompletely filled toward the anterior portion of the label field. For this case, we classified cells as pyramids or stellates only in the sections located in approximately the posterior third of the labeled field. Pyramidal cells were defined as those having an apical dendrite extending into L2/3. In cases where the tissue was cut in a pia-to-white matter plane, pyramidal cell classification was straightforward, as the majority of the apical dendrite extending into L2/3 could usually be visualized in one tissue section. For any neuron that appeared to be spiny stellate, the immediately adjacent tissue sections were reviewed to confirm the absence of an apical dendrite. For cases sectioned in the tangential plane, instead, all dendrites were either fully reconstructed through serial sections or marked with fiducial points and then followed up to L1, or until their termination. An apical dendrite in this tangential plane is generally easily identified as it is thicker in caliber than other dendrites and has a "corkscrew" appearance as it projects toward L2/3. Although this morphology is strongly indicative of a pyramidal cell, every dendrite for every cell was followed until its termination, and only cells with clear apical dendrites in L2/3 were considered pyramids.

For a detailed analysis of dendritic morphology, we fully reconstructed neurons through serial sections. For five injection cases that resulted in dense cell label, we reconstructed every labeled cell in one section, the one with the largest number of labeled cell bodies. However, in four injection cases with sparser cell label every labeled cell was reconstructed through all sections containing labeled neurons. As our initial analyses revealed a group of giant stellates projecting to thick, but not thin stripes, we reexamined label resulted from thin stripe injections, searching for large stellate neurons, and reconstructed the largest of them, to ensure that we had not under sampled from the thin stripe projecting neurons. Selected cells were reconstructed through serial sections on a Zeiss Axioskop light microscope connected to a QImaging color CCD camera, using $40 \times$ and $63 \times$ objectives, and Neurolucida software (MBF Bioscience; RRID: SCR_001775). To reconstruct cells across multiple serial sections, the section outline and large radial blood vessels were initially used for coarse alignment across sections. Fine-scale alignment was then achieved by matching local blood vessels and dendrite exit points to the adjacent section's local blood vessels and dendrite entry points. This process of using global and very local fiducial points allowed for highly accurate and complete reconstruction of dendrites.

\section{Statistical analyses}

The soma perimeter, soma area, dendritic length, dendritic field perimeter, dendritic field area, and dendritic field complexity were quantified for all reconstructed L4B neurons using Neurolucida software. The software uses a convex hull analysis to quantify dendritic field perimeter and area, and computes dendritic complexity according the following formula: (Sum of the terminal orders + Number of terminals $) \times($ Dendritic length/ Number of primary dendrites). Because of the mathematical relationships between some variables (e.g., soma area and soma perimeter), and correlations between all variables, we used principal component analysis (PCA) to control for correlations in the dataset, and to investigate factors that may be driving differences between samples in an unbiased way (Martínez et al., 2017). Stellate and pyramidal cells were analyzed separately, although combining all data yielded very similar results. Both analyses passed Bartlett's sphericity test $(p<0.001)$, and had Kaiser-Meyer-Oklin values $>0.68$, confirming the suitability of the analyses. The PCA analyses produced a single factor for both cell types that was clear from eigenvalues $(>4.5)$ or scree plot inspection, and accounted for 77 and $80 \%$ of the variance across morphological metrics for pyramids and stellates, respectively. All variables loaded strongly on the single factor $(>0.82)$. Next, to identify cell classes, hierarchical cluster analysis was performed on this PCA factor, using the Wards method and squared Euclidian distance (Cauli et al., 2000; Briggs et al., 2016; Yarch et al., 2017). Finally, one-way ANOVA analyses corrected for multiple comparisons using Bonferroni's correction were used to statistically compare groups identified by the cluster analysis across all morphological metrics. Other kinds of statistical analyses are reported in the Results. All analyses were performed using SPSS software (IBM).

\section{Results}

Guided by optical imaging, injections of GdRV-EGFP were targeted to V2 thick or thin stripes to assess the relative proportion of input to each stripe type arising from pyramidal and spiny stellate neurons in L4B of V1, as well as to investigate additional morphological characteristics of these cells. Figures $2 A-C$ and $3 A$ 


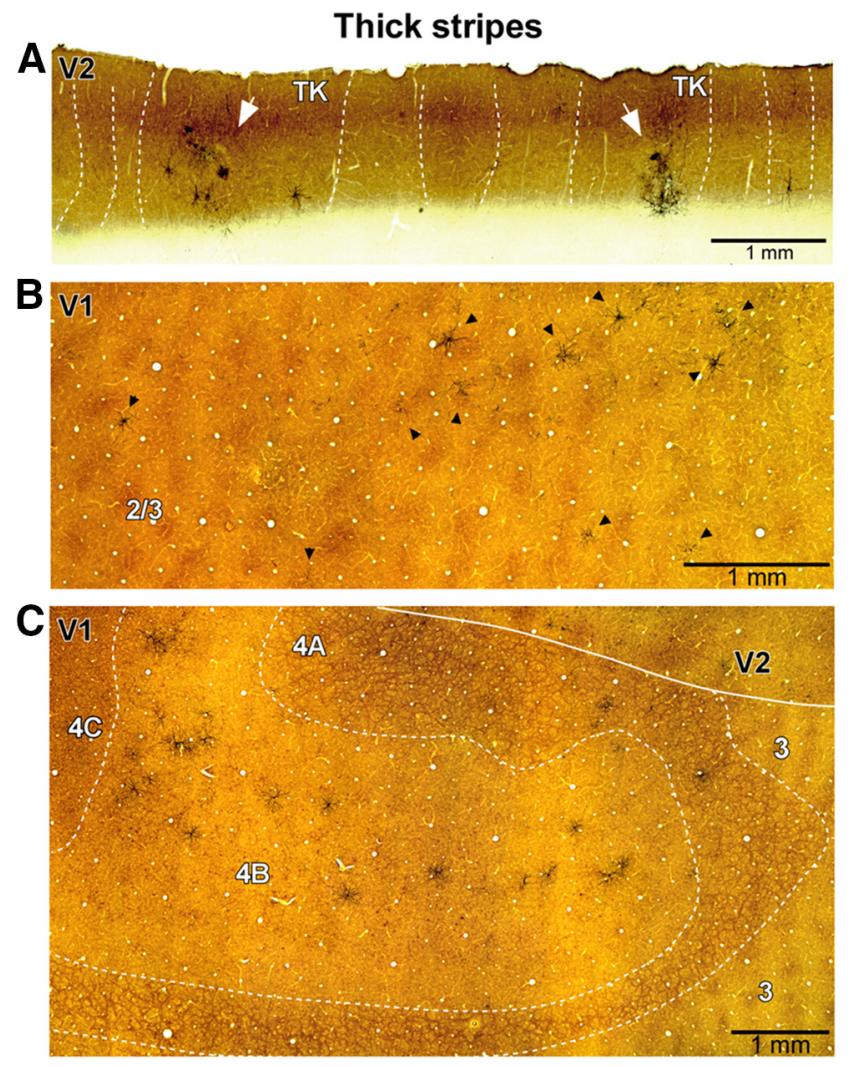

Figure 3. Injection sites in V2 thick (TK) stripes and resulting expression of GFP in V1 L4B neurons. Case MK368-N and -S. A, Micrograph of two example viral injection sites (arrows) on a merged stack of sections through V2 stained for $\mathrm{C} O$ and immunoreacted for GFP. The injections are located in thick stripes. Dashed white contours delineate thick and thin stripes. $\boldsymbol{B}$, Micrograph of a tangential section through V1 L2/3 stained for C 0 and immunoreacted for GFP, showing GFP-labeled cells (black cells marked by arrowheads) in L2/3 at C 0 blob borders and in inter-blobs, resulting from the thick stripe injections in A. C, Micrograph of a deeper tangential section through V1 L4A and L4B showing GFP-labeled cells resulting from the injections in $\boldsymbol{A}$. Dashed white contours delineate layer boundaries.

Table 1. Layer $4 \mathrm{~B}$ cell type percentages

\begin{tabular}{|c|c|c|c|c|c|c|}
\hline $\begin{array}{l}\text { V2 stripe } \\
\text { injected }\end{array}$ & Case & $\begin{array}{l}\text { No. of } \\
\text { stellates }\end{array}$ & $\begin{array}{l}\text { No. of } \\
\text { pyramids }\end{array}$ & $\begin{array}{l}\text { Total no. } \\
\text { of cells }\end{array}$ & $\begin{array}{l}\text { Percentage } \\
\text { stellate }\end{array}$ & $\begin{array}{l}\text { Average } \\
\text { percentage } \\
\text { stellate }\end{array}$ \\
\hline \multirow[t]{6}{*}{ Thick } & MK327 & 8 & 7 & 15 & 53 & \\
\hline & MK339 & 6 & 4 & 10 & 60 & \\
\hline & MK340 & 17 & 14 & 31 & 55 & 59 \\
\hline & MK368-N & 40 & 11 & 51 & 78 & \\
\hline & MK368-S & 8 & 8 & 16 & 50 & \\
\hline & Combined & 79 & 44 & 123 & 64 & - \\
\hline \multirow[t]{5}{*}{ Thin } & MK368-M & 18 & 21 & 39 & 46 & 32 \\
\hline & MK368-W & 8 & 18 & 26 & 31 & \\
\hline & MK371-M & 1 & 1 & 2 & 50 & \\
\hline & MK371-W & 0 & 1 & 1 & 0 & \\
\hline & Combined & 27 & 41 & 68 & 40 & - \\
\hline Thick + Thin & ALL & 106 & 85 & 191 & 55 & - \\
\hline V2 overall (Nassi and & JNM8 & 3 & 17 & 20 & 15 & 17 \\
\hline \multirow[t]{2}{*}{ (allaway, 2007) } & JNM12 & 20 & 92 & 112 & 18 & \\
\hline & Combined & 23 & 109 & 132 & 17 & - \\
\hline
\end{tabular}

depict four representative injection sites, two in thin and two in thick stripes, respectively. Injection location was determined based on optical imaging (OI) maps (Fig. 2A,B), CO histochemistry (Figs. $2 C, 3 A$ ), and the distribution of resulting labeled cells within V1 CO compartments (Figs. 2D, $3 B, C$ ). For example, for
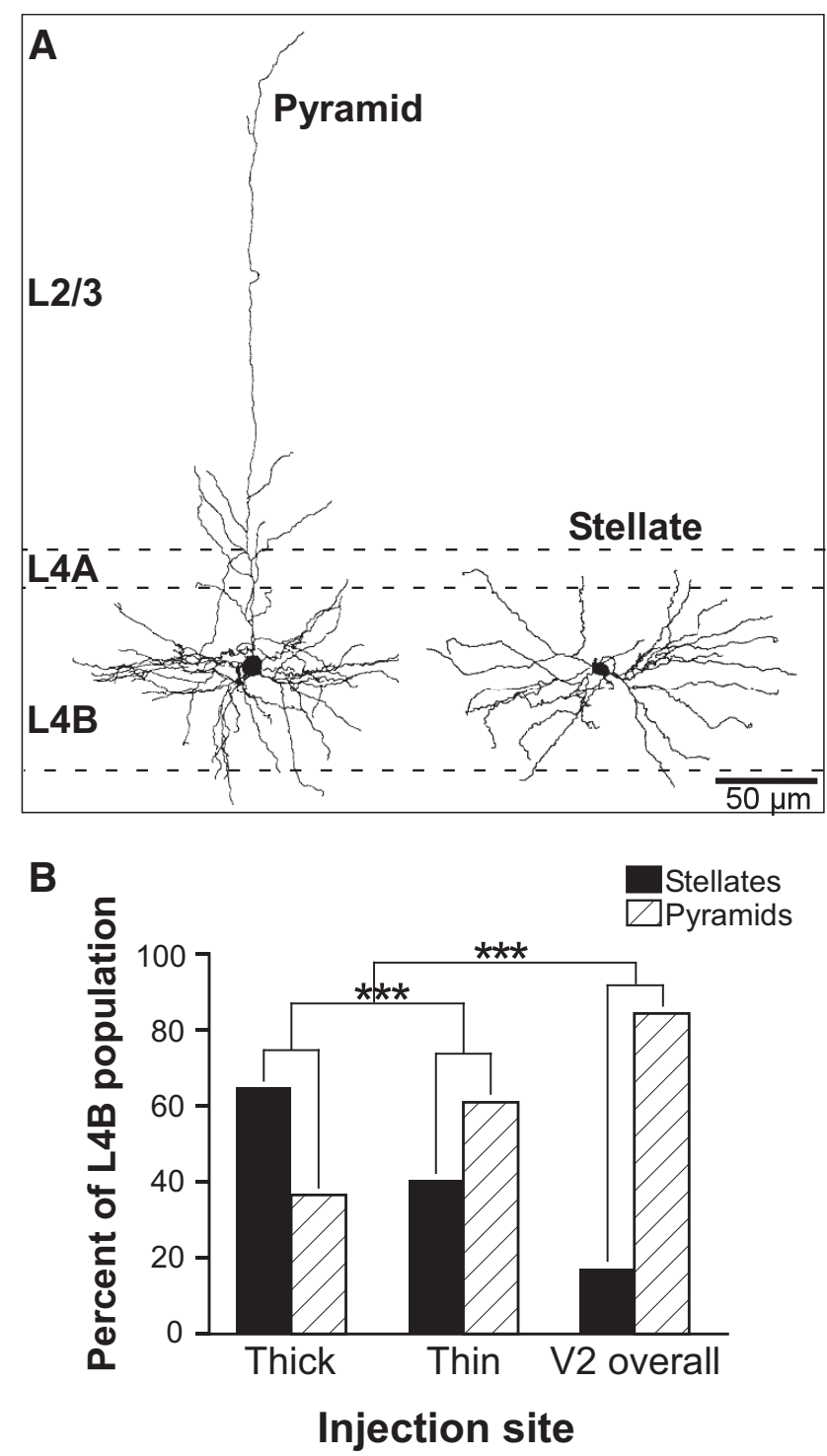

Figure 4. $L 4 B$ cell types projecting to thick or thin stripes. $A$, Computer-assisted, serial section, dendritic reconstructions of example pyramidal and spiny stellate cells. The pyramidal cell is distinguished by its apical dendrite ascending into the layers above 4B. The spiny stellate cell, instead, lacks an apical dendrite and largely restricts its dendrites to $L 4 B$. V1 layers are indicated. $B$, Average percentages of spiny stellate and pyramidal neurons projecting to thick or thin stripes, or to V2 overall (the latter are data from Nassi and Callaway, 2007). See also Table 1. Asterisks indicate statistically significant differences.

the case in Figures 1 and 2, alignment of histological sections containing injections sites to the most superficial tissue section, and of the latter to the optical maps (Fig. 1C,D; see Materials and Methods) demonstrated that the injections lay in regions of weak orientation signals and strong color responses (Figs. $1 \mathrm{~A}, \mathrm{~B}, 2 \mathrm{~A}-$ $C)$. These regions, corresponded well to thin stripes in $\mathrm{CO}$ stained sections, i.e., the narrower dark $\mathrm{CO}$ stripes flanked on either side by pale CO staining (Fig. 2C). Furthermore, important corroborating evidence for thin stripe injection site location was the presence of labeled neurons in L2/3 of V1 clustered within CO blobs (Fig. 2D), as expected based on previous connectivity studies (Livingstone and Hubel, 1984; Sincich and Horton, 2005). In contrast, following injections into thick stripes (Fig. $3 A$; for other examples of injection sites also used in this study, see Yarch et al., 2017), labeled cells in V1 L2/3, as expected, were found mostly 
Table 2. Layer 4B cell morphological measurements

\begin{tabular}{|c|c|c|c|c|c|c|c|c|}
\hline & & $\begin{array}{l}\text { Soma } \\
\text { perimeter, } \mu \mathrm{m}\end{array}$ & $\begin{array}{l}\text { Soma } \\
\text { area, } \mu m^{2}\end{array}$ & $\begin{array}{l}\text { Dendritic } \\
\text { length, }{ }^{a} \mu \mathrm{m}\end{array}$ & $\begin{array}{l}\text { Total dendritic } \\
\text { length, }{ }^{b} \mu \mathrm{m}\end{array}$ & $\begin{array}{l}\text { Dendritic } \\
\text { perimeter, }^{a} \mu \mathrm{m}\end{array}$ & $\begin{array}{l}\text { Dendritic } \\
\text { area }^{a}{ }^{a} \mu \mathrm{m}^{2}\end{array}$ & $\begin{array}{l}\text { Dendritic } \\
\text { complexity }^{a}\end{array}$ \\
\hline $\begin{array}{l}\text { V2 stripe } \\
\text { injected }\end{array}$ & Cell type $(n)$ & $\begin{array}{l}\text { mean } \pm \text { SEM } \\
\text { (min-max) }\end{array}$ & $\begin{array}{l}\text { mean } \pm \text { SEM } \\
(\text { min-max })\end{array}$ & $\begin{array}{l}\text { mean } \pm \text { SEM } \\
(\text { min-max })\end{array}$ & $\begin{array}{l}\text { mean } \pm \text { SEM } \\
(\text { min-max) }\end{array}$ & $\begin{array}{l}\text { mean } \pm \text { SEM } \\
(\text { min-max })\end{array}$ & $\begin{array}{l}\text { mean } \pm \text { SEM } \\
(\text { min-max })\end{array}$ & $\begin{array}{l}\text { mean } \pm \text { SEM } \\
(\text { min-max })\end{array}$ \\
\hline \multirow[t]{3}{*}{ Thick } & Stellates (20) & $\begin{array}{l}44.6 \pm 2.16 \\
(28.9-68.7)\end{array}$ & $\begin{array}{l}128.4 \pm 11.5 \\
(49.9-248.6)\end{array}$ & $\begin{array}{l}4,076.7 \pm 403.4 \\
(1,019.3-7542.5)\end{array}$ & $\begin{array}{l}4,076.7 \pm 403.4 \\
(1,019.3-7542.5)\end{array}$ & $\begin{array}{l}869.7 \pm 44.5 \\
(500-1390)\end{array}$ & $\begin{array}{l}53,038 \pm 6712.2 \\
(12,064-138,554)\end{array}$ & $\begin{array}{l}20,230 \pm 2557.9 \\
(8,703-45,534)\end{array}$ \\
\hline & Pyramids (20) & $\begin{array}{l}41 \pm 1.71 \\
(32.1-61.5)\end{array}$ & $\begin{array}{l}102.3 \pm 6.9 \\
(54.3-181.4)\end{array}$ & $\begin{array}{l}2,838.1 \pm 220.9 \\
(1,135.7-5292.8)\end{array}$ & $\begin{array}{l}3,162.7 \pm 216.4 \\
(1,436.4-5568.7)\end{array}$ & $\begin{array}{l}675.9 \pm 17.5 \\
(566.3-828.2)\end{array}$ & $\begin{array}{l}30,800 \pm 2093.1 \\
(17,040-52,144)\end{array}$ & $\begin{array}{l}15,000 \pm 1652.7 \\
(3,089.2-30,569)\end{array}$ \\
\hline & $\begin{array}{l}\text { Stellates + pyramids } \\
\text { (40) }\end{array}$ & $\begin{array}{l}42.8 \pm 1.39 \\
(28.9-68.7)\end{array}$ & $\begin{array}{l}115.3 \pm 6.94 \\
(49.9-248.6)\end{array}$ & $\begin{array}{l}3,457.4 \pm 247.7 \\
(1,019.3-7542.5)\end{array}$ & $\begin{array}{l}3,619.7 \pm 237.5 \\
(1,019.3-7542.5)\end{array}$ & $\begin{array}{l}772.8 \pm 28.2 \\
(500-1390.2)\end{array}$ & $\begin{array}{l}41,919 \pm 3900 \\
(12,064-138,554)\end{array}$ & $\begin{array}{l}17,615 \pm 1561 \\
(3,089.2-45,534)\end{array}$ \\
\hline \multirow[t]{3}{*}{ Thin } & Stellates (11) & $\begin{array}{l}44.7 \pm 2.34 \\
(32.5-55.4)\end{array}$ & $\begin{array}{l}143.6 \pm 14.9 \\
(78.5-222.7)\end{array}$ & $\begin{array}{l}3,653.6 \pm 312.8 \\
(1,327.8-4722.5)\end{array}$ & $\begin{array}{l}3,653.6 \pm 312.8 \\
(1,327.8-4722.5)\end{array}$ & $\begin{array}{l}856 \pm 42.4 \\
(610.9-1068.4)\end{array}$ & $\begin{array}{l}54,920 \pm 5358 \\
(26,240-82,628)\end{array}$ & $\begin{array}{l}24,530 \pm 3148.6 \\
(6,704.5-39,854)\end{array}$ \\
\hline & Pyramids (12) & $\begin{array}{l}46.2 \pm 2.1 \\
(37.2-59.9)\end{array}$ & $\begin{array}{l}147.2 \pm 13 \\
(68.8-216.9)\end{array}$ & $\begin{array}{l}3,545.2 \pm 293.3 \\
(2,137.9-5053)\end{array}$ & $\begin{array}{l}3,766.8 \pm 300.7 \\
(2,460-5259.1)\end{array}$ & $\begin{array}{l}727.5 \pm 22.3 \\
(632.6-842.6)\end{array}$ & $\begin{array}{l}39,066 \pm 2729.7 \\
(26,231-53,784)\end{array}$ & $\begin{array}{l}22,018 \pm 2648.5 \\
(8,864-41,183)\end{array}$ \\
\hline & $\begin{array}{l}\text { Stellates + pyramids } \\
\text { (23) }\end{array}$ & $\begin{array}{l}45.4 \pm 1.54 \\
(32.5-59.9)\end{array}$ & $\begin{array}{l}145.5 \pm 9.62 \\
(68.8-222.7)\end{array}$ & $\begin{array}{l}3,597 \pm 209.4 \\
(1,327.8-5053)\end{array}$ & $\begin{array}{l}3,712.7 \pm 212.1 \\
(1,327.8-5259.1)\end{array}$ & $\begin{array}{l}789 \pm 26.6 \\
(610.9-1068.4)\end{array}$ & $\begin{array}{l}46,648 \pm 3322 \\
(26,232-82,628)\end{array}$ & $\begin{array}{l}23,219 \pm 2014 \\
(6,704.5-41,183)\end{array}$ \\
\hline \multirow[t]{3}{*}{$\begin{array}{l}\text { V2 overall (Nassi and } \\
\text { Callaway, 2007) }\end{array}$} & Stellates & $\begin{array}{l}41.83 \pm 2.05 \\
(-) \\
{[n=15]}\end{array}$ & $\begin{array}{l}121.2 \pm 10.03 \\
(-) \\
{[n=15]}\end{array}$ & $\begin{array}{l}2,869.3 \pm 191.7 \\
(-) \\
{[n=3]}\end{array}$ & $\begin{array}{l}2,869.3 \pm 191.7 \\
(-) \\
{[n=3]}\end{array}$ & - & - & - \\
\hline & Pyramids & $\begin{array}{l}46.8 \pm 1.09 \\
(-) \\
{[n=55]}\end{array}$ & $\begin{array}{l}153.22 \pm 6.98 \\
(-) \\
{[n=55]}\end{array}$ & $\begin{array}{l}4,371.4 \\
(-) \\
{[n=5]}\end{array}$ & $\begin{array}{l}4,938.7 \pm 474.2 \\
(-) \\
{[n=5]}\end{array}$ & - & - & - \\
\hline & Stellates + pyramids & $\begin{array}{l}45.73 \pm 0.98 \\
(-) \\
{[n=70]}\end{array}$ & $\begin{array}{l}146.4 \pm 6.07 \\
(-) \\
{[n=70]}\end{array}$ & $\begin{array}{l}3,806.6 \\
(-) \\
{[n=8]}\end{array}$ & $\begin{array}{l}4,162.7 \pm 477.1 \\
(-) \\
{[n=8]}\end{array}$ & - & - & - \\
\hline
\end{tabular}

${ }^{a}$ For pyramids, Dendritic length, Perimeter, Area, and Complexity exclude apical dendrite.

${ }^{b}$ For pyramids, Total dendritic length includes the apical dendrite; for stellates, total dendritic length equals dendritic length.

outside CO blobs, in inter-blob compartments (Fig. $3 B$ ), and a larger fraction of cells were labeled in L4B (Fig. 3C).

Thick and thin stripes receive different proportions of inputs from L4B spiny stellates and pyramids

We analyzed data from 123 L4B cells labeled by five injections in thick stripes, and $68 \mathrm{~L} 4 \mathrm{~B}$ cells labeled by four injections in thin stripes (Table 1). The sample of labeled cells from thin stripe injections was smaller than that from thick stripe injections, as thin stripes receive a much smaller fraction of their input from L4B compared with thick stripes (Sincich et al., 2007, 2010; Federer et al., 2009).

Representative reconstructed spiny stellate and pyramidal cells are shown in Figure $4 A$. Of the total amount of cells labeled from thick stripe injections $(n=$ 123; pooled across injections), $64 \%$ were spiny stellates and $36 \%$ were pyramids, whereas only $40 \%$ of cells labeled from thin stripe injections were spiny stellates and $\sim 60 \%$ were pyramids (Fig. $4 B$; Table 1). Measuring the proportion of stellates for each case separately, and then averaging these proportions across cases, resulted in stellates representing 59\% of cells projecting to thick stripes and only $32 \%$ of cells projecting to thin stripes ( $\mathrm{Ta}-$ ble 1). The proportion of spiny stellate and pyramidal neurons projecting to thick versus thin stripes were significantly different from each other (Fisher's exact test; $p=0.001$; Fig. $4 B$ ).
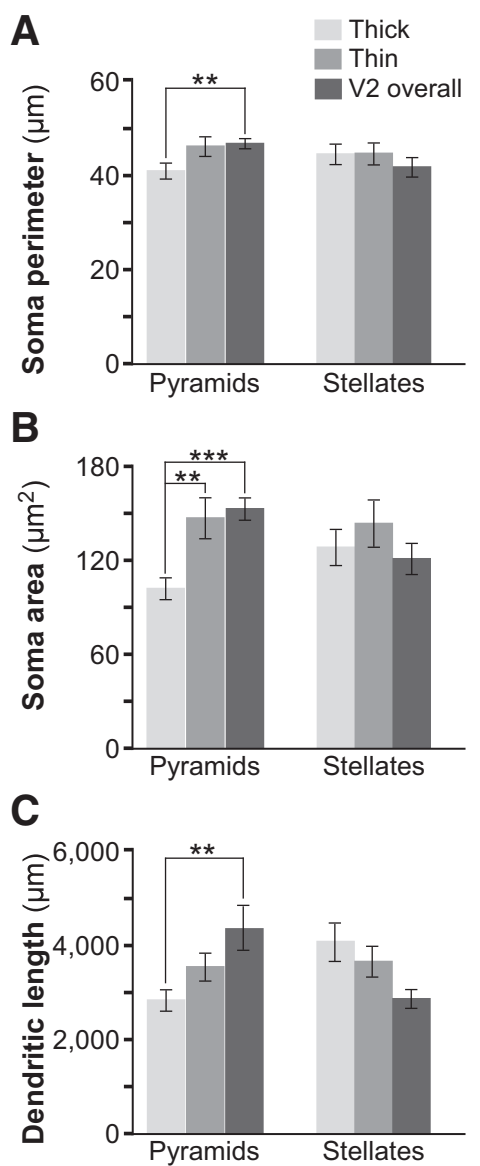

L4B cells projecting to V2

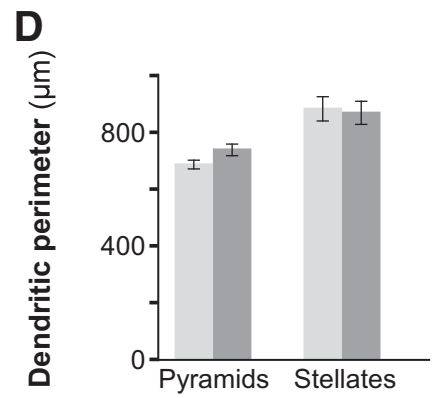

E

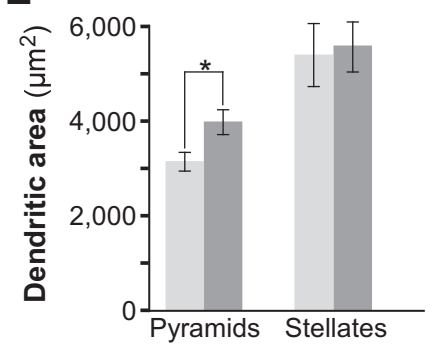

$\mathbf{F}$

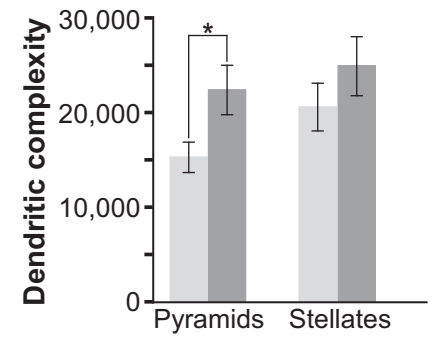

L4B cells projecting to V2

Figure 5. Morphological differences between $L 4 B$ neurons projecting to thick versus thin stripes. Average soma perimeter $(\boldsymbol{A})$ and area $(\boldsymbol{B})$, dendritic length $(\boldsymbol{C})$, perimeter $(\boldsymbol{D})$, area $(\boldsymbol{E})$, and complexity $(\boldsymbol{F})$ for spiny stellate and pyramidal cells projecting to thick or thin stripes or V2 overall (the latter are data from Nassi and Callaway, 2007). See also Table 2. Error bars indicate SEM. Asterisks indicate statistically significant differences. 
A
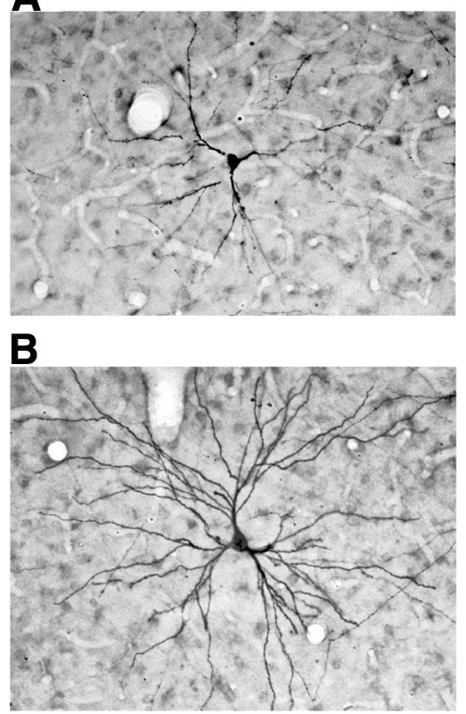

C

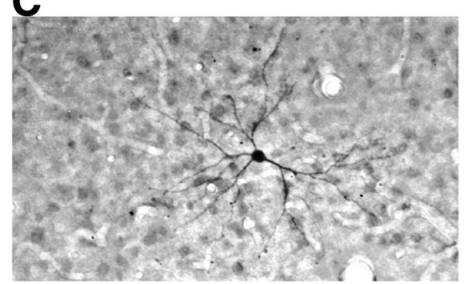

\section{D}

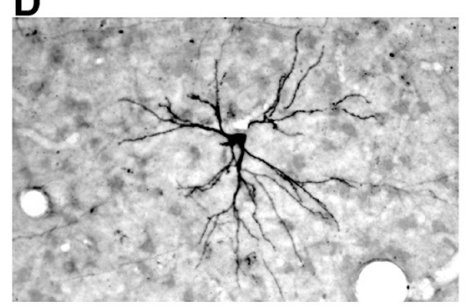

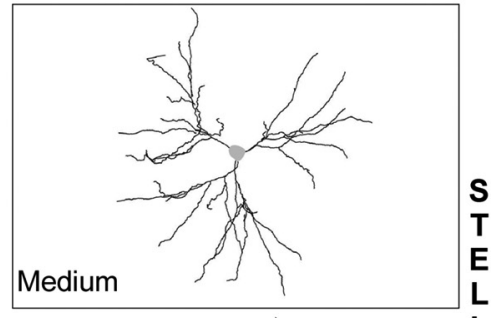
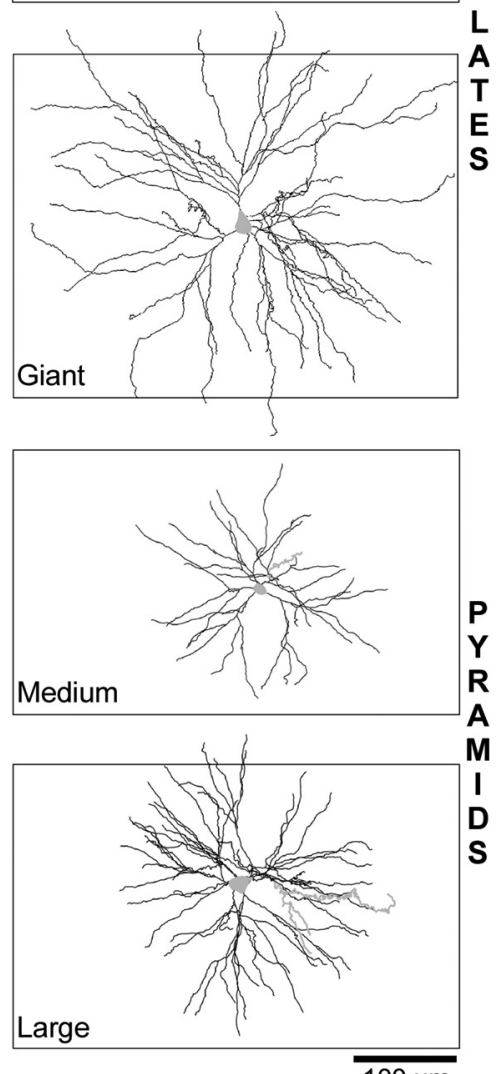

$100 \mu \mathrm{m}$

Figure 6. Morphological diversity of $L 4 B$ neurons projecting to V2 thick and thin stripes. $A-D$, Micrographs (left) and computerassisted serial section reconstructions (right) of example GFP-labeled $L 4 B$ neurons projecting to $\mathrm{V} 2$, demonstrating the variation in soma and dendritic size and complexity among these projection neurons. Micrographs were manipulated in Adobe Photoshop by increasing brightness and contrast and reducing unspecific background staining. Scale bar is valid for all panels.

We compared these results to those of a previous study (Nassi and Callaway, 2007) in which injections of the same virus as used in our study, but made blindly into V2 with no knowledge of the targeted stripe type, labeled only $17 \%$ of V1 L4B neurons with stellate morphology (Fig. 4B; Table 1). Both the proportions of stellates and pyramids projecting to thick $(p<0.0001)$ and thin $(p=0.0009)$ stripes in our sample were significantly different from those in the study by Nassi and Callaway (2007). Our results indicate that V2 thick and thin stripes receive a much larger contribution from stellate cells than V2 overall, and that the proportion of inputs from each L4B cell type is stripe-specific.

\section{Multiple L4B cell types project to thick and thin stripes}

Nassi and Callaway (2007) found that L4B cells projecting to MT are about twice as large as those projecting to V2, indicating that neuronal size is a distinguishing morphological feature of the L4B pathways to V2 and MT. We asked whether there are any differentiating morphological characteristics between L4B neurons that project to V2 thick versus thin stripes, as neurons in these stripes project to the dorsal versus ventral pathways, respectively.

We fully reconstructed and measured the soma perimeter, soma area, dendritic length, dendritic perimeter, dendritic area, and complexity of the dendritic field of $63 \mathrm{~L} 4 \mathrm{~B}$ cells projecting to V2, of which 40 (20 pyramids, 20 spiny stellates) projected to thick stripes, and 23 (12 pyramids, 11 stellates) projected to thin stripes (Table 2). All dendritic measurements (length, perimeter, area, and complexity) reported in the tables and figures and used for statistical analyses excluded the apical dendrites of pyramidal cells. We refer to these measurements as dendritic length, perimeter, area and complexity. However, in Table 2, we additionally report the total dendritic length of pyramidal cells, which includes these cell's apical dendrites; for spiny stellates, total dendritic length matches dendritic length, as these cells lack an apical dendrite. We found that pyramidal cells projecting to thick stripes tended to be smaller and less complex than the pyramids projecting to thin stripes (soma perimeter, $p=0.067$; soma area, $p=0.002$; dendritic length, $p=$ 0.062; dendritic field perimeter, $p=$ 0.079; dendritic field area, $p=0.022$; dendritic field complexity, $p=0.024$; Fig. 5; Table 2). It is likely that the marginally nonsignificant results for some of these metrics are due to our relatively small samples, as the differences in cells between stripes were consistent across all metrics. Additionally, we found that the pyramids projecting to thick stripes were significantly smaller than the pyramids projecting to V2 overall identified by Nassi and Callaway (2007) (soma perimeter, $p=$ 0.006; soma area, $p<0.001$; dendritic length, $p=0.006$; Fig. 5; Table 2). These results suggest that there may be at least two different morphologically distinct groups of pyramids projecting from L4B to V2. In contrast, we found no significant differences between spiny stellates projecting to thick versus thin stripes, at least with respect to the morphological metrics we examined (Fig. 5). However, similar to pyramids, stellate cells projecting to either stripe type showed a wide range of values across all morphological metrics we examined (Table 2; Fig. 6). For example, the dendritic length of spiny stellate neurons ranged from 1019 to $7543 \mu \mathrm{m}$ (Table 2), a sevenfold difference, with the largest values being comparable to those previously reported by Nassi and Callaway (2007) for the L4B cells projecting to MT (Fig. $6 B)$. Stellates projecting to thick or thin stripes were also not significantly different from stellates projecting to V2 overall identified by Nassi and Callaway (2007); however, relatively low sample sizes in both studies may have reduced the power to detect differences, because there was a tendency for stellates projecting to thick stripes to have larger dendritic length than stellates projecting to V2 overall ( $p=0.27$; Fig. $5 C$; Table 2 ). 
Table 3. Layer 4B pyramid morphological measurements

\begin{tabular}{|c|c|c|c|c|c|c|}
\hline & Soma perimeter, $\mu \mathrm{m}$ & Soma area, $\mu \mathrm{m}^{2}$ & Dendritic length, $\mu \mathrm{m}$ & Dendritic perimeter, $\mu \mathrm{m}$ & Dendritic area, $\mu \mathrm{m}^{2}$ & Dendritic complexity \\
\hline Cell class (n) & mean \pm SEM (min-max) & mean \pm SEM (min-max) & mean \pm SEM (min-max) & mean \pm SEM (min-max) & mean \pm SEM (min-max) & mean \pm SEM (min-max) \\
\hline Small (8) & $36.2 \pm 0.86(32.1-39.4)$ & $81.1 \pm 3.58(68.6-93.2)$ & $1,955 \pm 198.2(1136-2947)$ & $611.9 \pm 12(566.3-657)$ & $23,690 \pm 1698(17,040-30,852)$ & $8,785 \pm 1121(3089-13,266)$ \\
\hline Medium (17) & $41.4 \pm 1.07(33.1-48.9)$ & $112.0 \pm 6.43(54.3-166)$ & $3,088 \pm 136(2359-4114)$ & $688.5 \pm 12.8(592.1-754)$ & $32,587 \pm 1358(23,371-40,496)$ & $17,548 \pm 1316(7078-27,485)$ \\
\hline Large (7) & $54.3 \pm 2.37(44-61.5)$ & $179.8 \pm 11.3(140.2-216.9)$ & $4,453 \pm 272.2(3352-5293)$ & $807 \pm 11.1(770.3-842.6)$ & $48,756 \pm 1458(44,762-53,784)$ & $27,947 \pm 3170(16,866-41,183)$ \\
\hline
\end{tabular}

The wide range of morphological values detected within each cell group was suggestive of different cell types within a group, and prompted us to further analyze our neuronal sample. We performed PCA on all six variables (soma perimeter, soma size, dendritic length, dendritic perimeter, dendritic area, and complexity of the dendritic field), separately for pyramids and stellates pooled across stripe types, to determine how many factors might be driving differences between samples. The PCA analysis produced a single factor that accounted for 77 and $80 \%$ of the variance across morphological metrics for pyramids and stellates, respectively (see Materials and Methods).

We then performed hierarchical cluster analyses on the PCA factor separately for pyramids and stellates, pooled across stripe types, to determine whether neurons projecting to thick versus thin stripes could be differentiated, and whether there were different classes of neurons overall. For pyramids, this analysis revealed three classes of cells, which we have termed small, medium, and large (Figs. 6, 7A). The three pyramidal cell classes were significantly different from each other on all six morphological metrics (i.e., soma perimeter and area, as well as dendritic length, perimeter, area and complexity; Fig. 7B; Table 3), with small cells having smaller somas, as well as shorter and less complex dendritic trees extending over a smaller area compared with medium and large cells; vice versa large cells showed greater values for all these metrics than small and medium cells.

For spiny stellate cells, the analysis revealed four classes of neurons, which we have termed small, medium, large, and giant (Figs. 6, 8A). The four classes were significantly different from each other in soma perimeter and area, as well as dendritic perimeter and area. Additionally, small stellates had smaller dendritic length than all other classes, and medium stellates had smaller dendritic length compared with giant, but not large, cells. Finally, giant and large, but not medium stellates had greater dendritic complexity than medium and small stellates, but this metric did not differ between giant and large cells (Fig. $8 B$; Table 4).

With the exception of giant stellates, which were only found to project to thick stripes, we did not find a unique relationship between the remainder of pyramidal and stellate cell classes and

B
A Pyramidal cell classes
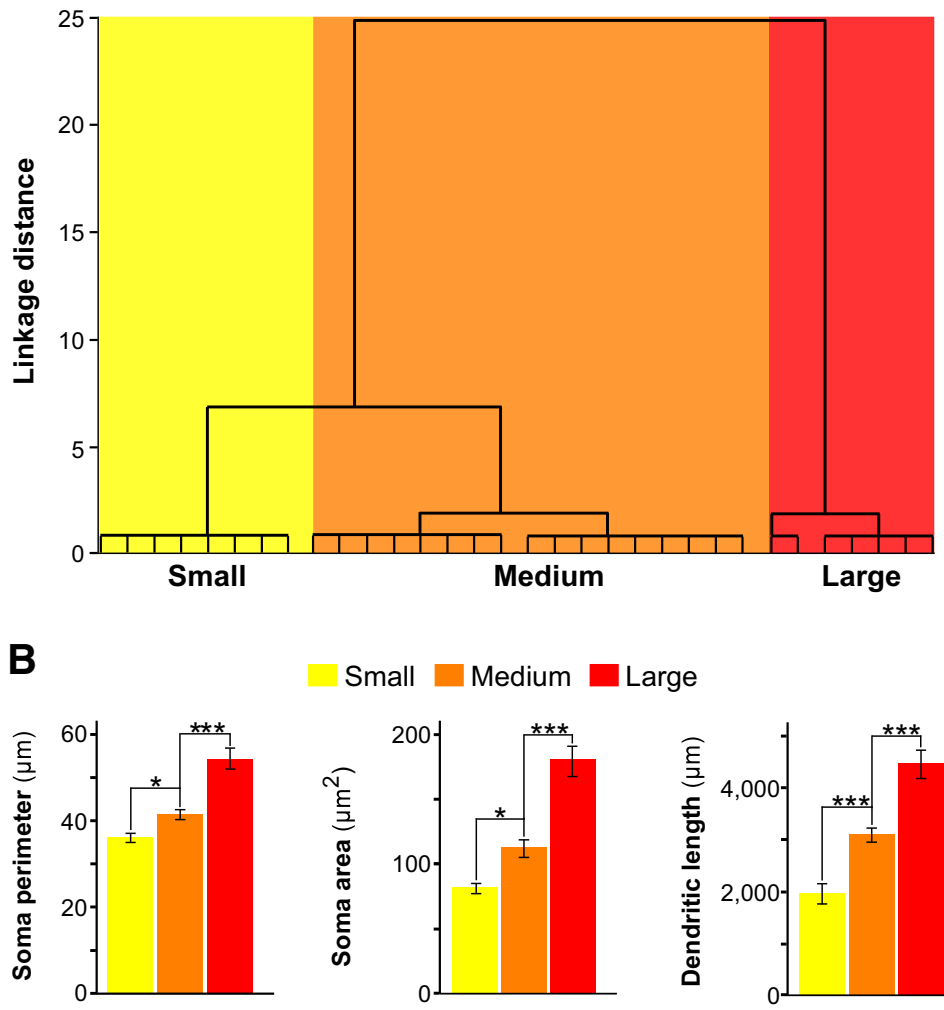

Small Medium $\square$ Large
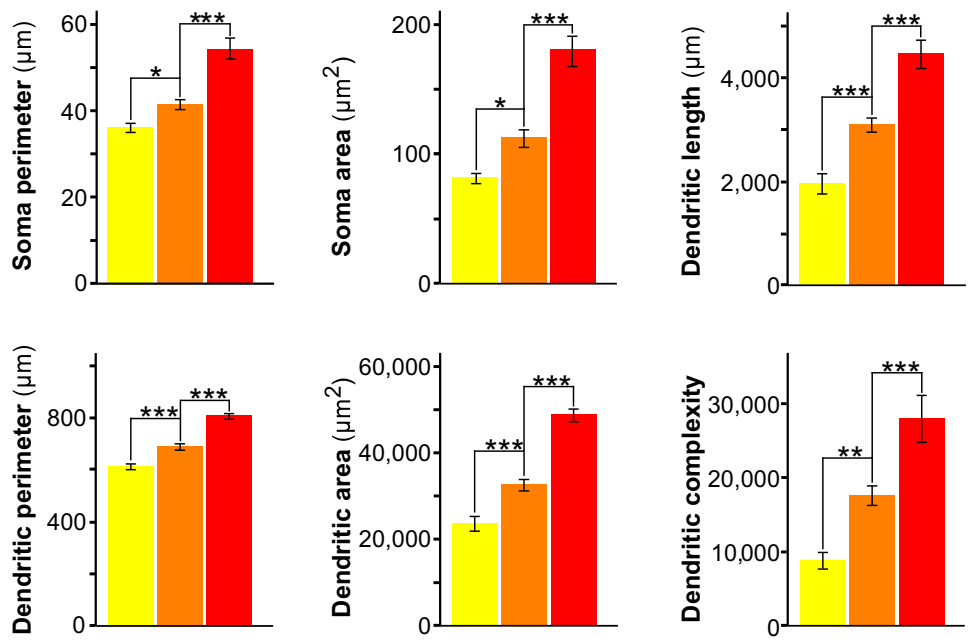

Figure 7. Classification of $\mathrm{L} 4 \mathrm{~B}$ pyramids projecting to $\mathrm{V} 2$ thick and thin stripes. A, Dendrogram of our population of fully reconstructed $\mathrm{L} 4 \mathrm{~B}$ pyramidal neurons $(n=32$ ) projecting to either thick or thin stripes, indicating the linkage distances (a ( clustering) of small (yellow), medium (orange) and large (red) cells. $\boldsymbol{B}$, Average soma perimeter and area dendritic length, perimeter, area, and complexity for each of the three different classes of cells. Asterisks indicate statistically significant differences. See also Table 3.

stripe type, as each of these classes comprised neurons projecting to both thick and thin stripes (Fig. 9). Moreover, thick and thin stripes received inputs from each pyramidal cell class in similar, albeit not identical proportions, with thick stripes receiving a larger fraction of small-sized pyramids and a smaller fraction of medium-sized pyramids compared with thin stripes (Fig. 9B). In contrast, although giant stellates only projected to thick stripes, the distribution of stellate classes projecting to thin stripes was skewed toward larger cells compared with stellates projecting to thick stripes (Fig. 9A). However, these differences between cell classes projecting to thick versus thin stripes were not statistically 
Table 4. Layer 4B stellate morphological measurements

\begin{tabular}{|c|c|c|c|c|c|c|}
\hline & Soma perimeter, $\mu \mathrm{m}$ & Soma area, $\mu \mathrm{m}^{2}$ & Dendritic length, $\mu \mathrm{m}$ & Dendritic perimeter, $\mu \mathrm{m}$ & Dendritic area, $\mu \mathrm{m}^{2}$ & Dendritic complexity \\
\hline Cell class $(n)$ & mean \pm SEM (min-max) & mean \pm SEM (min-max) & mean \pm SEM (min-max) & mean \pm SEM (min-max) & mean \pm SEM (min-max) & mean \pm SEM (min-max) \\
\hline Small (6) & $34.9 \pm 1.44(28.9-38.4)$ & $75.7 \pm 6.23(49.9-91.2)$ & $2,054 \pm 418.4(1019-3176)$ & $662.8 \pm 41(500-774.7)$ & $27,044 \pm 3590(12,063-34,807)$ & $10,263 \pm 1225(6705-15,402)$ \\
\hline Medium (15) & $42.3 \pm 1.24(33.7-50.9)$ & $118.7 \pm 5.81(85.1-156.6)$ & $3,772 \pm 275.9(2395-5785)$ & $828.2 \pm 21.8(697.3-1001)$ & $46,865 \pm 2946(30,399-74,626)$ & $18,291 \pm 2001(9215-39,854)$ \\
\hline Large (8) & $50.9 \pm 1.48(45.4-55.7)$ & $178.8 \pm 9.36(144.1-222.7)$ & $4,925 \pm 338(3856-7081)$ & $983.9 \pm 34(830.1-1101)$ & $70,697 \pm 5780(40,535-91,116)$ & $32,665 \pm 2046(20,982-40,108)$ \\
\hline Giant (2) & $65.6 \pm 3.15(62.4-68.7)$ & $241.4 \pm 7.22(234.1-248.58)$ & $6,710 \pm 832.5(5878-7543)$ & $1,269 \pm 120.8(1149-1390)$ & $117,028 \pm 21,526(95,502-138,554)$ & $38,587 \pm 6948(31,639-45,534)$ \\
\hline
\end{tabular}

A

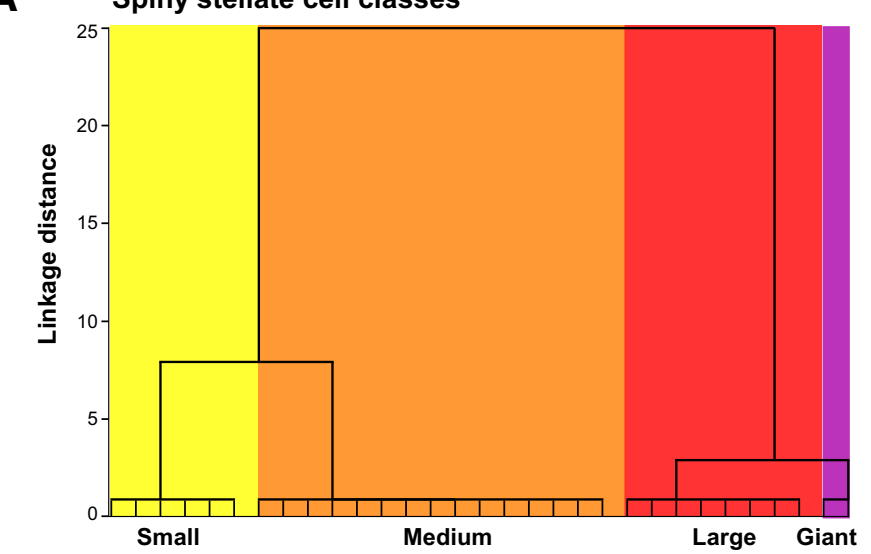

B
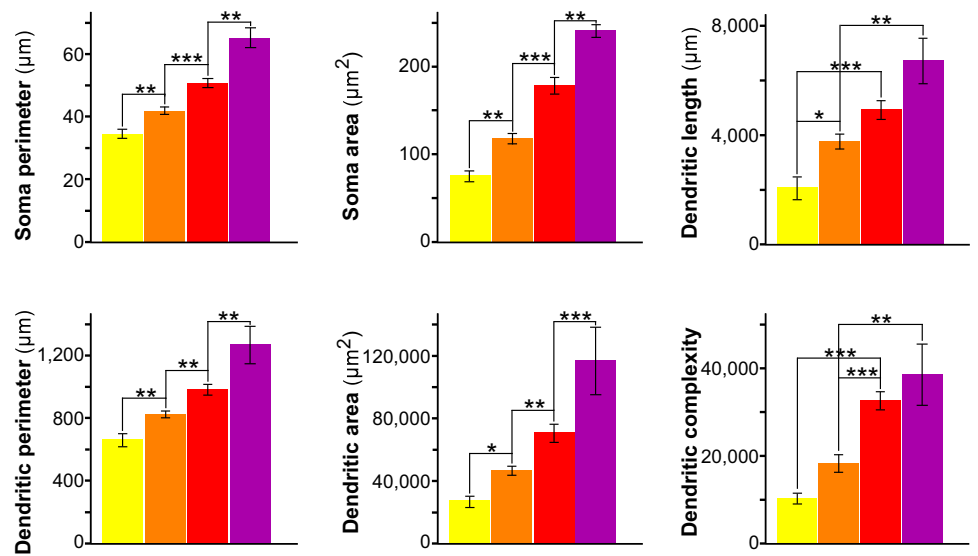

Figure 8. Classification of $L 4 B$ spiny stellates projecting to $V 2$ thick and thin stripes. $A$, Dendrogram of our population of fully reconstructed L $4 B$ spiny stellate neurons $(n=31)$ projecting to either thick or thin stripes, indicating the linkage distances of $S$ mall (yellow), medium (orange), large (red) and giant (purple) cells. $\boldsymbol{B}$, Average soma perimeter and area, dendritic length, perimeter, area and complexity for each of the four different classes of cells. Asterisks indicate statistically significant differences. See also Table 4.

significant (Fisher's exact test; $p \geq 0.076$ for all comparisons), perhaps because of the small samples of cells in each class (for cell numbers, see Fig. 9 legend).

As the different pyramidal and stellate cell classes identified by the cluster analysis were termed arbitrarily, we compared stellate cell classes with pyramidal cell classes to determine whether cells assigned to similar classes (e.g., small) indeed have similar soma and dendritic sizes. Medium stellates had significantly greater dendritic length (mean \pm SEM: $3772 \pm 275.9 \mu \mathrm{m}, p=0.028$, unpaired Student's $t$ test, equal variance assumed), larger dendritic perimeter $(828.2 \pm 21.8 \mu \mathrm{m}, p=0.000003$, $)$, and larger dendritic area $(46,865 \pm 2946 \mu \mathrm{m}, p=0.00008$, ) than medium pyramids (3088 $\pm 136 \mu \mathrm{m}, 688.5 \pm 12.8 \mu \mathrm{m}$, and 32,587 \pm 1358 $\mu \mathrm{m}$, respectively). Large stellates had significantly larger dendritic perimeter $(983.9 \pm 34.0 \mu \mathrm{m}, p<0.0005)$ and larger den- dritic area $(70,697 \pm 5781 \mu \mathrm{m}, p=$ 0.004 , ) than large pyramids $(807.0 \pm 11.1$ $\mu \mathrm{m}$ and $48,757 \pm 1458 \mu \mathrm{m}$, respectively; Fig. 10). Soma area and perimeter and dendritic complexity, instead, did not significantly differ between stellates and pyramids. We also found no differences between stellate or pyramidal cell classes projecting to thick versus thin stripes, i.e., medium pyramids or large stellates projecting to thick stripes were not different from medium pyramids or large stellates, respectively, projecting to thin stripes (data not shown).

\section{Discussion}

In this study, we aimed to determine the proportion of inputs from V1 L4B spiny stellate and pyramidal neurons to thick and thin CO compartments in V2. Additionally, we examined multiple morphological features of L4B neurons projecting to V2, to assess whether thick and thin stripe-projecting cells could be differentiated from each other on the basis of other morphological characteristics. We found that thick and thin stripes receive different proportions of inputs from L4B spiny stellates and pyramids, with thick stripes receiving $\sim 60 \%$ and thin stripe only $40 \%$ of their inputs from stellates. Notably, these proportions of input to thick and thin stripes differ significantly from the $~ 20 \%$ L4B stellate input found by Nassi and Callaway (2007) to V2 overall. Moreover, quantification of soma and dendritic field size and complexity revealed different classes of neurons projecting to thick and thin stripes. Small, medium, and large pyramids and stellates project to both stripe types, but giant stellates, similar to those previously found to project to MT (Nassi and Callaway, 2007), were only found to project to thick stripes.

The different proportions of L4B stellate and pyramidal input to thick and thin stripes found in our study have several implications for the functional circuitry of the primate visual system. First, our finding of a much greater proportion of M-dominated stellate input to both thick and thin stripes than previously shown for V2 overall (Nassi and Callaway, 2007) indicates that there is a much greater amount of $\mathrm{M}$ input flowing into both the ventral stream, via thin stripes, and the dorsal stream, via thick stripes, than previously assumed. Second, the greater proportion of input from stellate cells to thick compared with thin stripes, suggests a stronger contribution of the M pathway, via area V2, to the dorsal 

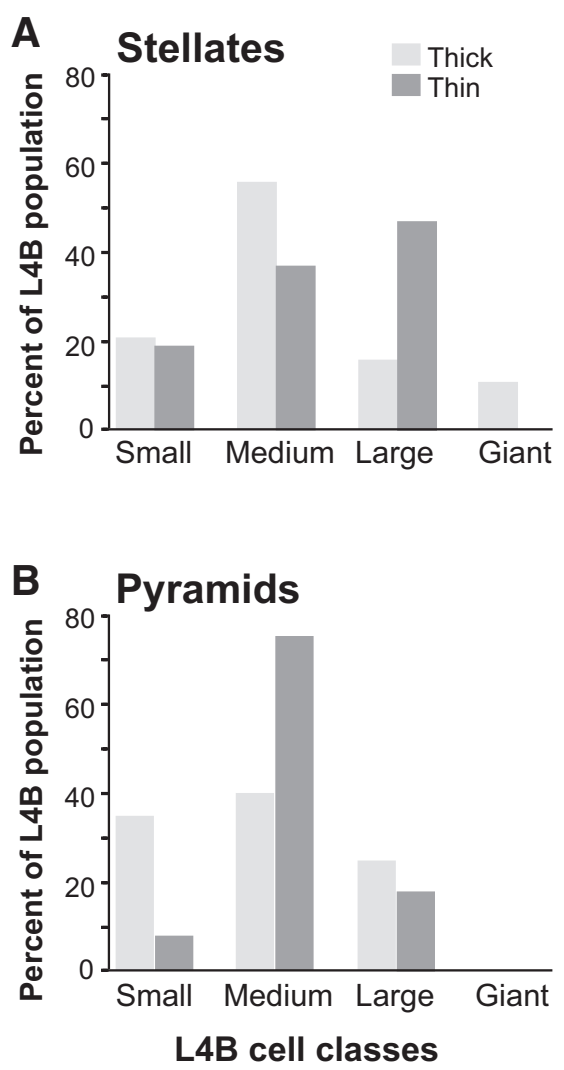

Figure 9. Contributions of different $L A B$ cell classes to thick and thin stripes. $A$, Percentage of the $L 4 B$ spiny stellate cell population projecting to thick and thin stripes that arises from each stellate cell class (thick stripes: $n=4$ small, 11 medium, 3 large, 2 giant stellates; thin stripes: $n=2$ small, 4 medium, 5 large, 0 giant stellates). $\boldsymbol{B}$, Percentage of the L4B pyramidal cell population projecting to thick and thin stripes that arises from each pyramidal cell class (thick stripes: $n=7$ small, 8 medium, 5 large, 0 giant pyramids; thin stripes: $n=1$ small, 9 medium, 2 large, 0 giant pyramids).

stream than to the ventral stream. Together with previous evidence that L4B input to area MT arises predominantly from M-dominated spiny stellate cells (Nassi and Callaway, 2007), our results support the notion that the dorsal stream is dominated by the M pathway. However, our finding that $\sim 40 \%$ of inputs to thick stripes arise from L4B pyramidal cells, whose apical dendrites have access to both M-dominated L4C $\alpha$ and P-dominated L4C $\beta$ inputs (Yabuta and Callaway, 1998), indicate that the dorsal stream also receives $\mathrm{P}$ information via the thick stripes. It has long been known that, beyond the LGN and L4C of V1, where M and $\mathrm{P}$ pathways are segregated, there is substantial convergence of these pathways (Lachica et al., 1992; Yoshioka et al., 1994; Yabuta and Callaway, 1998; Yabuta et al., 2001), and that both the dorsal and ventral visual streams receive a mixture of $\mathrm{M}$ and $\mathrm{P}$ information (Merigan and Maunsell, 1993). Nevertheless, the striking specificity of intra-V1 connections (Lund, 1988) and of connections between V1 and V2 stripes (Federer et al., 2009, 2013; Yarch et al., 2017) suggests that V1 may relay specific combinations of $\mathrm{M}$ and $\mathrm{P}$ input to V2 stripes. Our results show specific proportions of $\mathrm{M}$ and $\mathrm{P}$ inputs that are conveyed from $\mathrm{L} 4 \mathrm{~B}$ of $\mathrm{V} 1$ into the dorsal and ventral streams, via the V2 thick and thin stripes, respectively.

Nassi and Callaway (2007) found that the L4B input to V2 overall is $\sim 20 \%$ of spiny stellate origin, as opposed to the $80 \%$ spiny stellate input to MT. This contrasts with the $\sim 40$ and $60 \%$ L4B stellate input to thin and thick stripes, respectively, found in
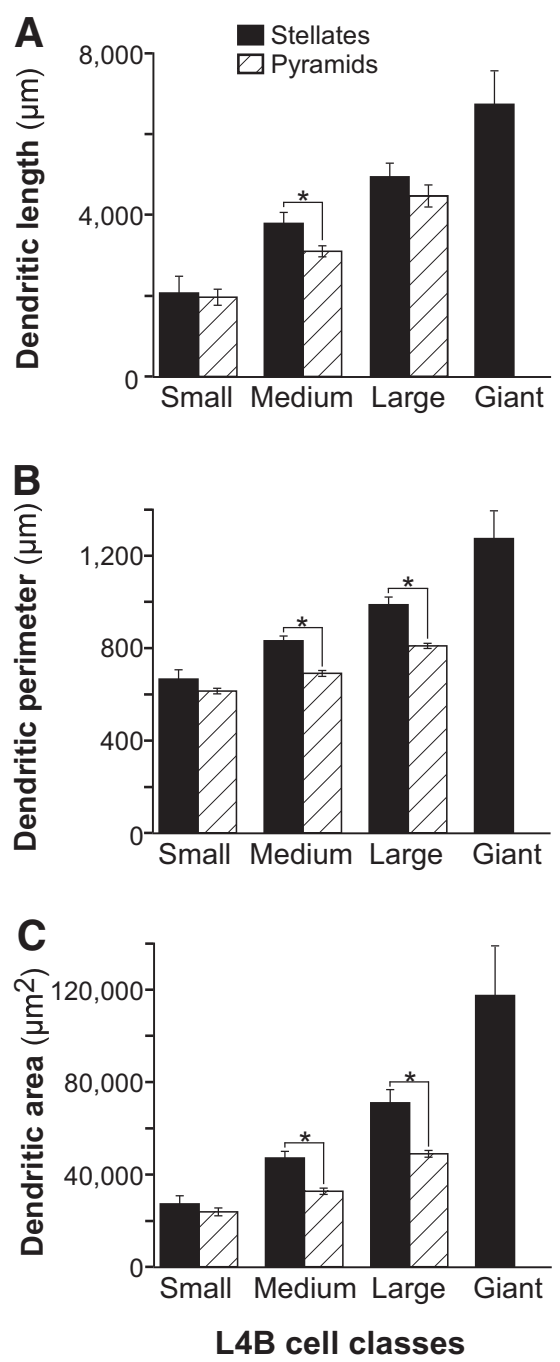

Figure 10. Comparison of pyramidal and stellate cell classes. Average dendritic length $(\boldsymbol{A})$ perimeter $(\boldsymbol{B})$, and area $(\boldsymbol{C})$ for the four different classes of stellate (black bars) and pyramids (hashed bars). Asterisks indicate statistically significant differences.

our study. Across all our injections (excluding one that labeled only one cell), the lowest percentage of stellates we found was $31 \%$ (following a thin stripe injection). Of the 191 cells that constituted our total cell sample, $55 \%$ were stellates, three times the largest percentage of stellates ( $18 \%$ of 132 cells) found by Nassi and Callaway (2007). The difference between our results and those of Nassi and Callaway (2007) could be because of multiple factors. Pale stripes, or pale and thin stripes, may have been the main targets of random injections made into V2 by Nassi and Callaway (2007). This is also suggested by the additional finding that the pyramids projecting to thick stripes in our study were significantly smaller than the pyramids projecting to V2 overall in the study by Nassi and Callaway (2007). It is possible that thin and pale stripes were preferentially targeted in the study by Nassi and Callaway (2007), particularly because the viral injections in that study were spaced at regular intervals (2 or $10 \mathrm{~mm}$ ), and pale and thin stripes account for $\sim 2 / 3$ of the V2 stripe cycle. This would suggest that pale stripes receive dominant, if not exclusive, L4B input from pyramidal cells, particularly those of larger size. An alternative interpretation is that different V2 functional subdomains or layers were injected, or the virus differentially infected different populations of L4B cells in the two studies. 
Our morphological characterization and analyses of cells projecting to V2 revealed different morphological types of L4B projection neurons, distinguishable on the basis of size and complexity, but was largely unable to differentiate between those projecting to thick versus thin stripes. Small, medium, and large stellate and pyramidal cells were found to project to both thick and thin stripes, although each may underpin different functional subcircuits between V1 and a given stripe type. However, morphological characterization alone can be insufficient for neuronal classification; therefore, we cannot exclude that small, medium and large spiny stellates and pyramids projecting to different $\mathrm{V} 2$ stripes differ in other properties that were not examined in our study, e.g., in their responses to visual stimuli or in their molecular phenotype. Genetically-based approaches for cell classification, similar to those recently used in rodent studies (Paul et al., 2017), may, in the future, help reveal distinct classes of small, medium, and large L4B stellates and pyramids projecting to specific V2 stripe types. Our morphological characterization, however, revealed one rare cell type, the giant stellate, as a possible differentiating feature between thick and thin stripe input from L4B. As we only found two such cells, we cannot exclude that a rare projection from giant cells may also exist to thin stripes. However, we are confident that no giant cells were labeled in our tissue after thin stripe injections, as we reconstructed every labeled large cell in our thin-stripe projecting L4B sample. Therefore, it is likely that the giant stellate cells constitute a rare population of neurons projecting only to thick stripes. These cells were of comparable size to the spiny stellate cells previously found to project only to MT (Nassi and Callaway, 2007), suggesting the existence of two fast M-dominated L4B pathways to the dorsal stream, one via MT, the other via the V2 thick stripes. It is also possible that the giant $\mathrm{L} 4 \mathrm{~B}$ stellate neurons that project to the $\mathrm{V} 2$ thick stripes represent a small population of V2-projecting neurons that also send axon collaterals to MT; this would be consistent with previous observations of large L4B somata double labeled from retrograde tracer injections into MT and V2 (Sincich and Horton, 2003).

Overall, the different groups of L4B neurons identified in this study as projecting to $\mathrm{V} 2$ suggests that there is not a single stereotyped L4B pyramid or stellate cell type sending output to V2. Instead, based on the morphological metrics examined here, there could be at least four different types of $\mathrm{L} 4 \mathrm{~B}$ cells projecting to V2. Greater dendritic length endows neurons with a greater capacity to integrate spatial information and receive more extensive input from other neurons. The larger cells we have identified may be integrating information across multiple stimulus dimensions, such as object motion and retinal disparity, whereas the smaller cells may have simpler response properties, such as motion or orientation tuning, functions previously associated with L4B neurons (Dow, 1974; Poggio and Fischer, 1977; Blasdel and Fitzpatrick, 1984). Additionally, greater dendritic length allows cells to encompass a larger area of visual cortex, and therefore of visual field, with their dendritic field, endowing them with larger receptive fields compared with smaller cells. Whatever the functional roles of these morphologically identified groups of neurons, different physiological functions often follow from different morphological features.

Overall, our results further demonstrate that circuits between brain areas, here V1 and V2 thin and thick stripes, can be heterogeneous. We have previously shown that different classes of cells can be revealed when neuronal populations are identified by their projection targets and interlaminar projections (Yarch et al., 2017). Here, we further this concept and show that the input to
V2 arising from V1 L4B differs for thin versus thick stripes, and importantly, from $\mathrm{V} 2$ overall. These results underline the importance of identifying a neuron's projection target in the mission to discover and understand cortical circuits, and indicate that characterization of neurons without this knowledge can be inaccurate or misleading.

\section{References}

Anderson JR, Jones BW, Yang JH, Shaw MV, Watt CB, Koshevoy P, Spaltenstein J, Jurrus E, Kannan UV, Whitaker RT, Mastronarde D, Tasdizen T, Marc RE (2009) A computational framework for ultrastructural mapping of neural circuitry. PLoS Biol 7:e1000074.

Blasdel GG, Fitzpatrick D (1984) Physiological organization of layer 4 in macaque striate cortex. J Neurosci 4:880-895.

Blasdel GG, Lund JS (1983) Terminations of afferent axons in macaque striate cortex. J Neurosci 3:1389-1413.

Briggs F, Kiley CW, Callaway EM, Usrey WM (2016) Morphological substrates for parallel streams of corticogeniculate feedback originating in both V1 and V2 of the macaque monkey. Neuron 90:388-399.

Cauli B, Porter JT, Tsuzuki K, Lambolez B, Rossier J, Quenet B, Audinat E (2000) Classification of fusiform neocortical interneurons based on unsupervised clustering. Proc Natl Acad Sci U S A 97:6144-6149.

Chen G, Lu HD, Roe AW (2008) A map for horizontal disparity in monkey V2. Neuron 58:442-450.

Dacey DM (2000) Parallel pathways for spectral coding in primate retina. Annu Rev Neurosci 23:743-775.

Dacey DM, Peterson BB, Robinson FR, Gamlin PD (2003) Fireworks in the primate retina: in vitro photodynamics reveals diverse LGN-projecting ganglion cell types. Neuron 37:15-27.

DeYoe EA, Van Essen DC (1985) Segregation of efferent connections and receptive field properties in visual area V2 of the macaque. Nature 317: $58-61$.

Dow BM (1974) Functional classes of cells and their laminar distribution in monkey visual cortex. J Neurophysiol 37:927-946.

Federer F, Ichida JM, Jeffs J, Schiessl I, McLoughlin N, Angelucci A (2009) Four projections streams from primate V1 to the cytochrome oxidase stripes of V2. J Neurosci 29:15455-15471.

Federer F, Williams D, Ichida JM, Merlin S, Angelucci A (2013) Two projection streams from macaque $\mathrm{V} 1$ to the pale cytochrome oxidase stripes of V2. J Neurosci 33:11530-11539.

Hendrickson AE, Wilson JR, Ogren MP (1978) The neuroanatomical organization of pathways between the dorsal lateral geniculate nucleus and visual cortex in old world and new world primates. J Comp Neurol 182: 123-136.

Kaplan E, Shapley RM (1986) The primate retina contains two types of ganglion cells, with high and low contrast sensitivity. Proc Natl Acad Sci U S A 83:2755-2757.

Krubitzer LA, Kaas JH (1990) Cortical connections of MT in four species of primates: areal, modular and retinotopic pattern. Vis Neurosci 5:165204.

Lachica EA, Beck PD, Casagrande VA (1992) Parallel pathways in macaque monkey striate cortex: anatomically defined columns in layer III. Proc Natl Acad Sci U S A 89:3566-3570.

Livingstone MS, Hubel DH (1984) Anatomy and physiology of a color system in the primate visual cortex. J Neurosci 4:309-356.

Livingstone MS, Hubel DH (1987) Connections between layer 4B of area 17 and the thick cytochrome oxidase stripes of area 18 in the squirrel monkey. J Neurosci 7:3371-3377.

Livingstone MS, Hubel DH (1988) Segregation of form, color, movement, and depth: anatomy, physiology, and perception. Science 240:740-749.

Lu HD, Roe AW (2008) Functional organization of color domains in V1 and V2 of macaque monkey revealed by optical imaging. Cereb Cortex 18: $516-533$

Lu HD, Chen G, Tanigawa H, Roe AW (2010) A motion direction map in macaque V2. Neuron 68:1002-1013.

Lund JS (1988) Anatomical organization of macaque monkey striate visual cortex. Annu Rev Neurosci 11:253-288.

Martínez JJ, Rahsepar B, White JA (2017) Anatomical and electrophysiological clustering of superficial medial entorhinal cortex interneurons. eNeuro 4:ENEURO.0263-16.2017

Merigan WH, Maunsell JH (1993) How parallel are the primate visual pathways? Annu Rev Neurosci 16:369-402. 
Nassi JJ, Callaway EM (2007) Specialized circuits from primary visual cortex to V2 and area MT. Neuron 55:799-808.

Paul A, Crow M, Raudales R, He M, Gillis J, Huang ZJ (2017) Transcriptional architecture of synaptic communication delineates GABAergic neuron identity. Cell 171:522-539.e20.

Poggio GF, Fischer B (1977) Binocular interaction and depth sensitivity in striate and prestriate cortex of behaving rhesus monkey. J Neurophysiol 40:1392-1405.

Rodieck RW, Watanabe M (1993) Survey of the morphology of macaque retinal ganglion cells that project to the pretectum, superior colliculus, and parvicellular laminae of the lateral geniculate nucleus. J Comp Neurol 338:289-303.

Schiller PH, Malpeli JG (1978) Functional specificity of lateral geniculate nucleus laminae of the rhesus monkey. J Neurophysiol 41:788-797.

Shipp S, Zeki S (1985) Segregation of pathways leading from area V2 to areas V4 and V5 of macaque monkey visual cortex. Nature 315:322-325.

Shipp S, Zeki S (1989) The organization of connections between areas V5 and V1 in macaque monkey visual cortex. Eur J Neurosci 1:309-332.

Sincich LC, Horton JC (2002) Divided by cytochrome oxidase: a map of the projections from V1 to V2 in macaques. Science 295:1734-1737.

Sincich LC, Horton JC (2003) Independent projection streams from macaque striate cortex to the second visual area and middle temporal area. J Neurosci 23:5684-5692.

Sincich LC, Horton JC (2005) Input to V2 thin stripes arises from V1 cytochrome oxidase patches. J Neurosci 25:10087-10093.

Sincich LC, Jocson CM, Horton JC (2007) Neurons in V1 patch columns project to V2 thin stripes. Cereb Cortex 17:935-941.
Sincich LC, Jocson CM, Horton JC (2010) V1 interpatch projections to V2 thick stripes and pale stripes. J Neurosci 30:6963-6974.

Ungerleider LG, Haxby JV (1994) "What" and "where" in the human brain. Curr Opin Neurobiol 4:157-165.

Watanabe M, Rodieck RW (1989) Parasol and midget ganglion cells of the primate retina. J Comp Neurol 289:434-454.

Wickersham IR, Finke S, Conzelmann KK, Callaway EM (2007) Retrograde neuronal tracing with a deletion-mutant rabies virus. Nat Methods 4:47-49.

Xiao Y, Wang Y, Felleman DJ (2003) A spatially organized representation of color in macaque cortical area V2. Nature 421:535-539.

Xu X, Ichida JM, Allison JD, Boyd JD, Bonds AB, Casagrande VA (2001) A comparison of koniocellular, magnocellular and parvocellular receptive field properties in the lateral geniculate nucleus of the owl monkey (Aotus trivirgatus). J Physiol 531:203-218.

Yabuta NH, Callaway EM (1998) Functional streams and local connections of layer $4 \mathrm{C}$ neurons in primary visual cortex of the macaque monkey. J Neurosci 18:9489-9499.

Yabuta NH, Sawatari A, Callaway EM (2001) Two functional channels from primary visual cortex to dorsal visual cortical areas. Science 292:297-300

Yarch J, Federer F, Angelucci A (2017) Local circuits of V1 layer 4B neurons projecting to V2 thick stripes define distinct cell classes and avoid cytochrome oxidase blobs. J Neurosci 37:422-436.

Yoshioka T, Levitt JB, Lund JS (1994) Independence and merger of thalamocortical channels within macaque monkey primary visual cortex: anatomy of interlaminar projections. Vis Neurosci 11:467-489. 